\title{
State-of-the-Art Review on Responses of RC Structures Subjected to Lateral Impact Loads
}

\author{
Chunwei Zhang $^{1}$ (D) $\cdot$ Gholamreza Gholipour ${ }^{1}$ (D) Asma Alsadat Mousavi ${ }^{1}$ (D)
}

Received: 27 November 2019 / Accepted: 6 July 2020 / Published online: 14 July 2020

(c) The Author(s) 2020

\begin{abstract}
Reinforced concrete structures and structural members used in strategic infrastructures such as highway bridges, high-rise buildings, etc. are inherently subjected to lateral impact loads arising from the collision of vehicles, vessels, falling rocks, and rigid objects having different impact geometries, weights, and velocities. Due to the brittle nature of concrete materials, both localized and overall failure modes are very likely to occur in concrete structures under dynamic and impulsive loads. Hence, many attempts have been carried out in the literature to recognize the failure behaviors and to assess the vulnerability of concrete structure under lateral impact loads. This paper presents a comprehensive state-of-the-art review on the responses and failure behaviors of various types of concrete structures and structural members subjected to lateral impact loads based on analytical, numerical, and experimental studies carried out by the previous research works. In addition, the influences of various structural- and load-related parameters on the impact resistance and failure behaviors of different concrete structures under lateral impact loads are reviewed.
\end{abstract}

\section{Introduction}

Owing to rapidly increasing the construction of reinforced concrete (RC) structures all over the world, the need for recognizing the responses of such structures exposed to dynamic and extreme loading conditions such as impact and blast loads is a very topic of importance. RC structures may be subjected to lateral impact loads arising from the falling of heavy rocks and objects, collision of vehicles and vessels, or from the high-velocity impacts of relatively lighter projectiles and rockets. Impact loading is a dynamic and extreme loading type which its duration may reach 1000 times shorter than earthquakes. Impact loads can be characterized into three types based on their intensity and duration $\left(t_{d}\right)$. These types are: (1) quasi-static loading in which the structure reaches its maximum response before ending of the impact duration; (2) dynamic loading in which the structure

Chunwei Zhang

zhangchunwei@qut.edu.cn

Gholamreza Gholipour

gh.gholipour@qut.edu.cn

Asma Alsadat Mousavi

as.mousavi@qut.edu.cn

1 School of Civil Engineering, Qingdao University of Technology, Qingdao 266033, China reaches its maximum response almost at the same time with the ending of the impact duration; (3) impulsive loading in which impact duration ends before reaching the structure its maximum response. Accordingly, structural components can demonstrate different behaviors under concentrate lateral impact loads including localized and overall responses as shown in Fig. 1. When a structural member is subjected to high-rate impact loading with very short duration relative to the structure natural period $(T)$, the stress wave propagation and inertia resistance of the structure is predominant on the responses. Under this loading condition, it is more expected to observe localized failure in the structure. However, when this ratio $\left(t_{d} / T\right)$ is large, the structural responses and failure modes are dependent on the stiffness of the structure and the structure tends to fail in overall modes [1].

Another classification of impact loadings based on their dissipative mechanism was proposed by Eurocode [3] including: (1) hard impact in which the initial kinetic energy was dissipated by striking objects such as colliding of vessels and vehicles with deformable bows with concrete structures, and (2) soft impact in which the major part of the initial kinetic energy was dissipated by the impacted structure such as impacting the rocks and rigid objects on concrete structures. Two simplified approaches using single-degree-of-freedom (SDOF), and two-degree-offreedom (2-DOF) models were recommended by Eurocode 
[3] to formulate and identify the overall responses of concrete structures under soft and hard impacts as shown in Fig. 2. In the proposed SDOF model, a partial mass of the impacted member exposed to a distributed (non-concentrated) impact load is idealized with a mass point element connected to a discrete (i.e., spring) element representing the global stiffness of the member under an equal concentrated dynamic load. However, the stiffness of both global and local structural responses are idealized connected to the relevant partial masses.

Although many simplified approaches exist in the current design codes to predict the responses of RC structures under impact loads, they are not able to obtain the brittle damage behaviors of concrete structures during high-rate and impulsive impact loads. Concrete structures might suffer localized failure modes and damages such as brittle spalling, scabbing, perforation, and punching shear failure $[5,6]$ under high-rate impact loads, or overall failure modes under rather low-rate impact loads as shown in Fig. 3.

Generally, several design codes define the estimation of impact loads and the simplified responses of structures subjected to different types of lateral impact loads especially those arising from vessels [7-9] and vehicles [8, 10-12] collisions using equivalent static and quasi-static analyses. However, the amplification dynamic effects such as inertia and strain rate effects have not been taken into account by these guidelines. Table 1 summarizes the impact load provisions considered by several design guidelines.

Studying the impact responses of structures under impact loads is possible through the main three approaches including simplified analytical, finite element (FE) numerical simulation, and experimental tests. In general, there exist some limitations in the use of simplified analytical approaches. As such, these techniques not only omit the structural dynamic behaviors such as inertia and strain rate

Fig. 1 Impact response modes of RC beams [2]
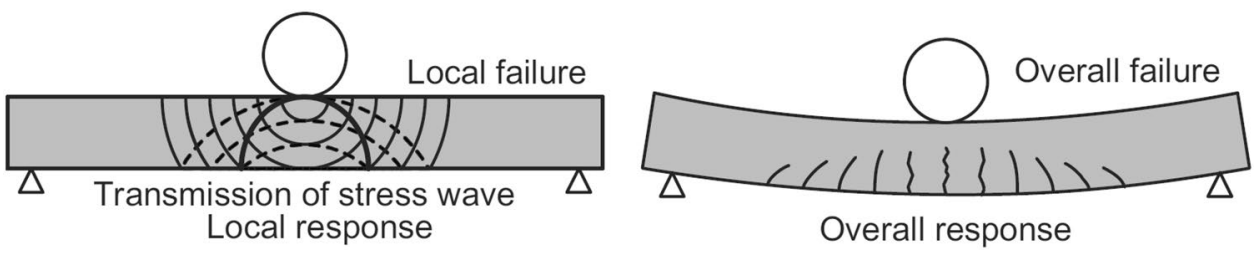

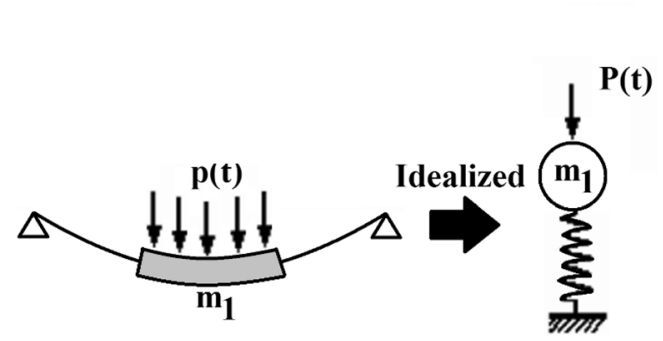

SDOF model for soft impact

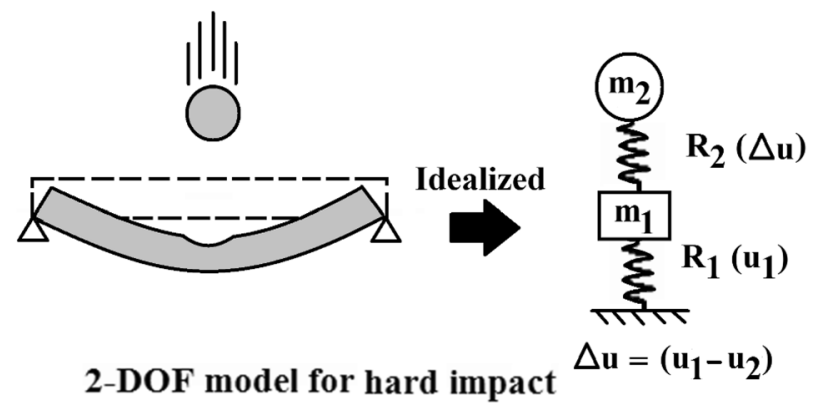

Fig. 2 Simplified models recommended by Eurocode [3] for the design of structures under impact loads [4]
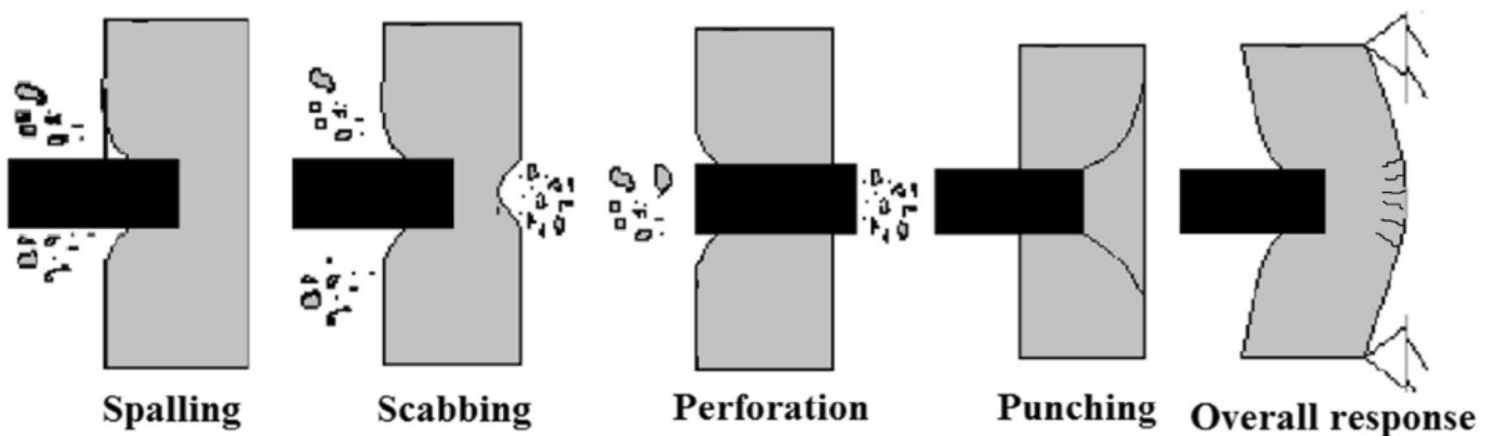

Fig. 3 Typical failure modes of concrete structures under different impact loads [5, 6] 
Table 1 Summary of current guidelines considering impact loading

\begin{tabular}{|c|c|c|}
\hline Guideline & Loading & Remarks and notes \\
\hline \multirow[t]{2}{*}{ AASHTO $[7,10]$} & Vessel collision & $\begin{array}{l}\text { Equivalent static load based on deformation-force data and kinetic energy of head-on vessel } \\
\text { collisions }\end{array}$ \\
\hline & Vehicle collision & $\begin{array}{l}\text { Equivalent static impact force full-scale crash tests of tractor-trailers/truck-barriers collisions } \\
\text { (derived not directly from head-on impact tests). Considering a 1800-kN static force applied } \\
\text { to the height of } 1.35 \mathrm{~m} \text { from the column base }\end{array}$ \\
\hline JSCE [13] & Rock falls & $\begin{array}{l}\text { Performance-based design structures under especially falling objects (e.g., rock falls) using the } \\
\text { equivalent mean impact forces and absorbed energy }\end{array}$ \\
\hline AS $1170.1[14]$ & Vehicle collision & $\begin{array}{l}\text { Equivalent static impact load based on the kinetic energy of vehicles with masses between the } \\
\text { ranges } 1500-2000 \mathrm{~kg}\end{array}$ \\
\hline \multirow[t]{2}{*}{$\mathrm{CEN}[3,8]$} & Vehicle collision & $\begin{array}{l}\text { Equivalent static force with considering the effects of impact velocity, impact angle, mass dis- } \\
\text { tribution, deformation behavior and damping characteristics of both impact and the structure } \\
\text { (ranges of maximum impact forces: } 1000 \mathrm{kN} \text { for tuck, and } 500 \mathrm{kN} \text { for car impacts) }\end{array}$ \\
\hline & Vessel collision & $\begin{array}{l}\text { Equivalent static force based on deformation energy of the vessel with considering the influ- } \\
\text { ences impact angle }\end{array}$ \\
\hline UK's highways agency [15] & Vehicle collision & $\begin{array}{l}\text { Equivalent nominal loads applying horizontally on bridge piers based on experimental tests } \\
\text { (between the ranges } 250 \mathrm{kN} \text { and } 1000 \mathrm{kN} \text { ) }\end{array}$ \\
\hline CMR [9] & Vessel collision & $\begin{array}{l}\text { Equivalent static load based on the kinetic energy of impacting ships (with considering impact } \\
\text { angle) }\end{array}$ \\
\hline
\end{tabular}

effects of the materials but also they are not able to capture the brittle failures and damage behaviors of structures under extreme loads. Besides, although the experimental tests give chances for accurately and reasonably evaluating the structural responses in the real world, conducting such tests needs notable professional equipment and economical resources. Compared to experimental approaches, FE numerical methods provide appropriate alternatives to conduct the test scenarios by reducing the time and costs along with obtaining accurate and reasonable results. There are many available commercial software codes such as LS-DYNA [16], and ABAQUS [17] to numerically simulate impact tests by adopting various contact algorithms between the striking and stuck components.

Impact loading tests can be also simulated in laboratory scales using different designed experimental facilities as follows:

- Drop weight impact facility The impactor with a certain mass is vertically released from a specified height regarding the desired impact energy as shown in Fig. 4a. [2]. This facility is the most common experimental method used to study the impact responses of concrete members placed horizontally such as beams [2, 18-20], and slabs [21, 22].

- Pendulum impact facility The impactor can be released from different angles in order to generate different initial impact energy as shown in Fig. 4b. [23, 24].

- Horizontal impact facility The impactor collides with the structure horizontally with a specified initial velocity as shown in Fig. 4c. [25, 26].
This paper aims to presents a state-of-the-art review on the responses and failure behaviors of various types of concrete structures and structural members including columns, bridge piers, beams, and slabs under different types of impact loads arising from the collision of rigid objects (i.e., soft impacts), or vehicles and vessels (i.e., hard impacts). The influences of different structural- and loading-related parameters on the impact resistance concrete structures are reviewed. In addition, the theoretical background, current design guidelines, and existing approaches for analyzing structures under impact loadings are reviewed.

\section{Bridge Piers Subjected to Impact Loads}

Columns are mainly axial load-carrying structural members that are commonly used in large-scale civil structures and infrastructures such as high-rise buildings, highway bridges, subways, etc. Impact loads arising from the collision of vessels or vehicles with RC columns used in bridges, low-rise buildings, and isolated traffic structures can be taken place during accidental events or intentional terrorist attacks. There exist many research works in the literature investigating the responses of $\mathrm{RC}$ bridge piers subjected to lateral impact loads from the collisions of vehicles [8, 10-12, 27-51], vessels [7-9, 52-67], shipping objects [68], and falling rocks $[69,70]$. Due to the significant discrepancies between the force-deformation behaviors of striking vehicles and vessels, and also different structural characteristics of impacted bridge piers (e.g., pier size and dimensions, substructure, boundary conditions, etc.), it is expected to 


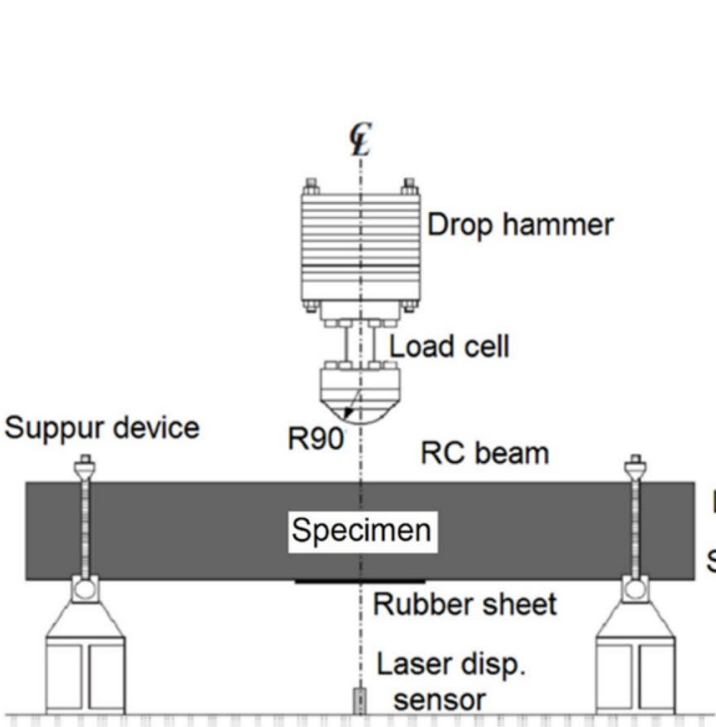

(a) Drop weight impact test [2]

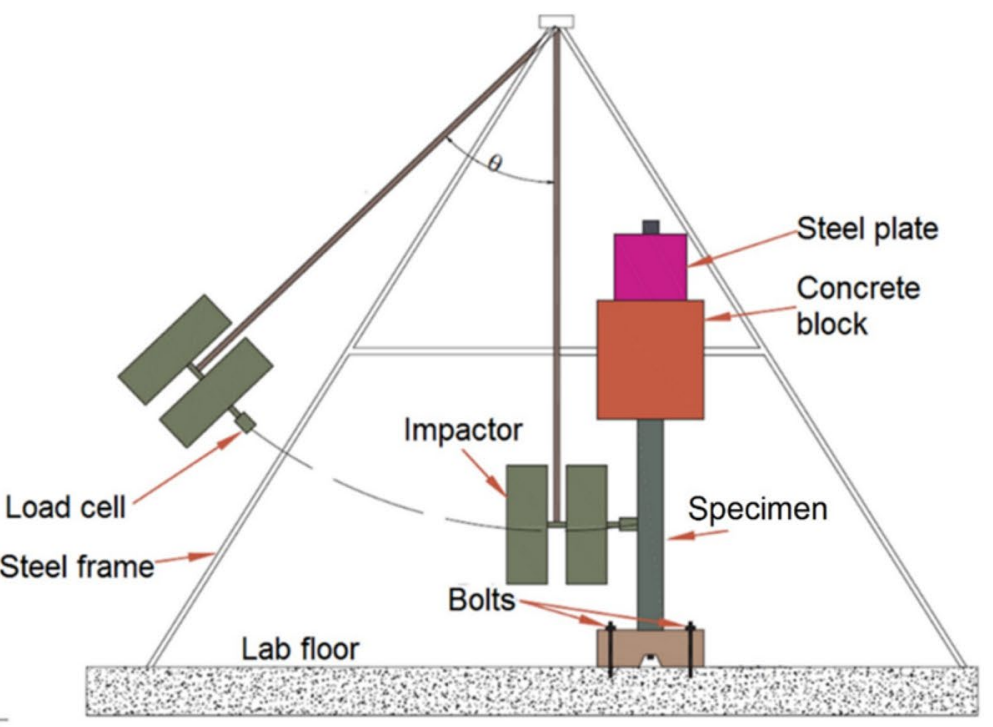

(b) Pendulum impact test [24]

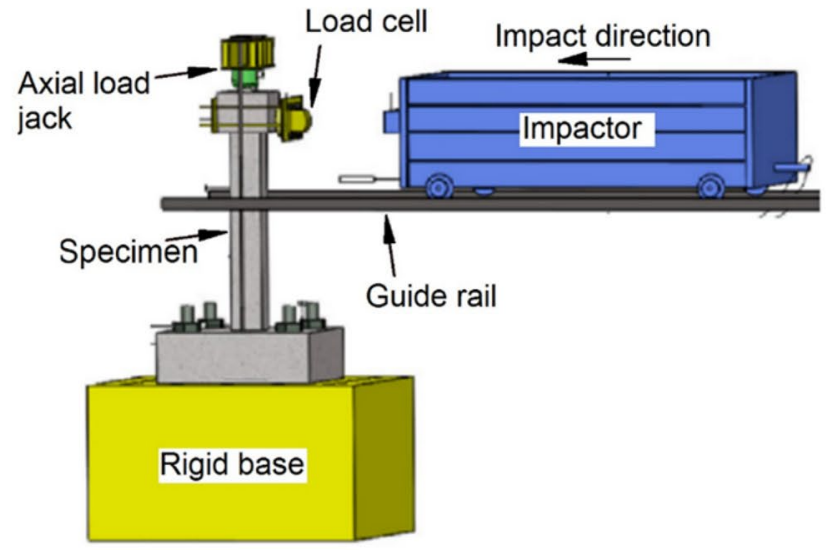

(c) Horizontal impact test [25]

Fig. 4 Impact loading test facilities

capture relatively different dynamic responses under vehicle collisions compared to those from vessel collisions. Hence, it is focused in this section on the review of existing analysis approaches and previous studies on the impact responses of $\mathrm{RC}$ bridge piers under vehicle and vessel collisions.

\subsection{Bridge Piers Subjected to Vehicle Collisions}

From the review study on the failure causes of 114 bridges by Harik et al. [71] during a 38-year period from 1951 to 1988 in the USA, it was found that $15 \%$ of these failures occurred due to truck collisions. In addition, based on a report by Wardhana and Hadipriono [72], about 3\% of 503 bridges in the USA were failed due to vehicle collision during an 11-year period from 1989 to 2000 in the USA. Two examples of bridge pier and superstructure failures are illustrated in Fig. 5.

The influences of various structural- and loading related parameters on the vehicle collision force and the structural responses of the impacted pier have been widely evaluated in the literature.

A parametric study was done by Zhou et al. [41] on the impact responses of RC bridge piers varying in terms of several parameters including impact velocity, impact mass, and the strengths of the pier concrete and steel reinforcements. Compared to the marginal influences of the concrete strength on the magnitude and duration of impact force, and the pier global deformations, the strength of steel reinforcements had substantial effects on the pier deformations. In addition, three performance levels including the local damage, flexural-shear failure, and cross-sectional fracture with shear 
(a)

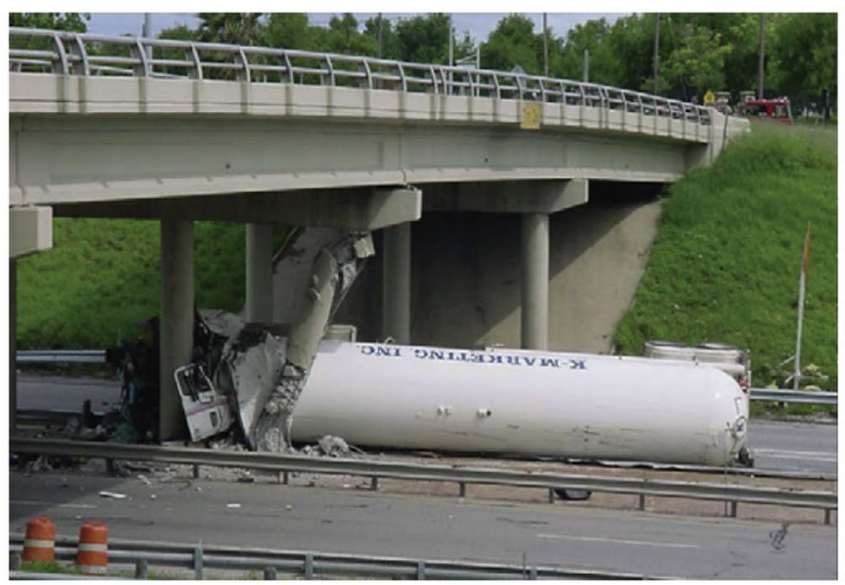

(b)

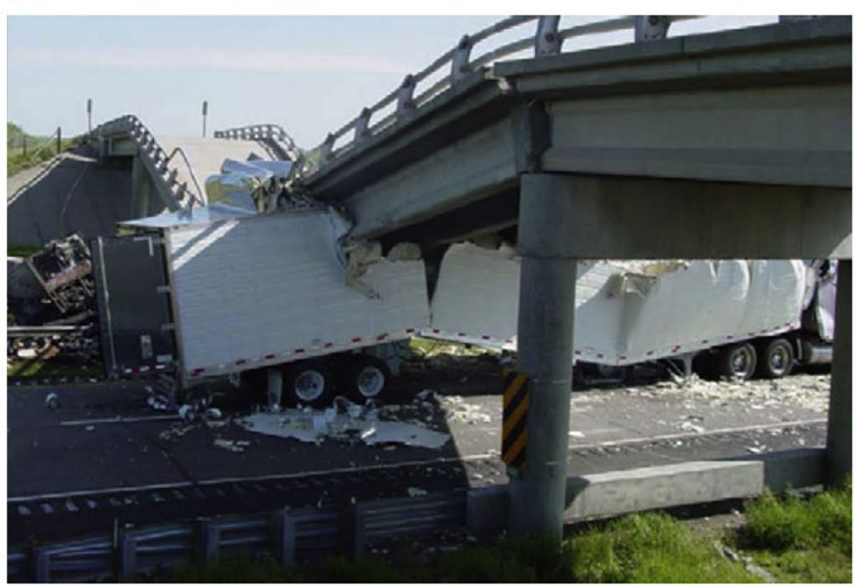

Fig. 5 a Failure of bridge column due to truck collision [73], b collapse of bridge superstructure after colliding a tractor-trailer [27]

failure of the pier from the FE simulations. Furthermore, a damage index based on the ratio of impact force to the shear capacity of bridge piers was proposed by Zhou and Li [42] using FE numerical simulations to describe different damage levels of bridge piers subjected to vehicle collisions.

Abdelkarim and ElGawady [34] carried out an extensive parametric study of RC bridge piers numerically by under different the collision of different vehicles, the positive influences of reinforcement ratio, column cross-sectional dimensions, axial load level, material strain rate effects, and impact velocity and weight of vehicle were found on the peak value of impact force. However, it was not affected by the variability of concrete strength, pier boundary condition, and the depth of soil surrounding the pier base.

Compared to several proposed simplified models of the vehicle-pier collision system proposed by Al-Thairy and Wang [74], Milner et al. [75], and Vrouwenvelder [76], Chen et al. [37] proposed a more sophisticated system using a reduced coupled mass-spring-damper (CMSD) model. From the evolution of different parameters, it was revealed that except the marginal effects of vehicle weight, other parameters including impact velocity, pier geometry, and the material properties of the pier had significant influences on the impact force results. Afterwards, the proposed simplified CMSD model utilized by Chen et al. [38] to assess the validation of a proposed spectrum-based design method in the prediction of impact responses of piers. In addition, an equivalent frame model (scaled model) of a large-size truck was designed by Chen et al. [39] to use in collision with RC bridge piers experimentally. The experimental test results revealed the significant influences of impact velocity and mass on the structural and impact responses. The influences of cross-sectional shape and dimensions of RC piers, striking truck cargo weight, impact velocity, impact position, and vehicle type were numerically evaluated by Chen et al. [45] on the impact force results during heavy truck collisions with $\mathrm{RC}$ bridge piers. It was obtained that the first peak of impact force was more sensitive to the impact velocity, while the following peaks were more sensitive to the impact weight. In addition, the shape and diameter of the impacted pier had marginal influences on the impact force results. Yi et al. [47] concluded that RC columns with circular cross-sectional shape suffered larger displacements and more severe damage levels under tuck collision rather than those with square shape. Moreover, from a sensitivity analysis of column impact resistance to the axial load ratio and the concrete strength, no influence trend of these parameters was obtained.

Fan et al. [28] numerically studied the impact responses and the performance of ultra-high-performance fiber-reinforced concrete (UHPFRC)-strengthened bridge piers compared to those with normal concrete in the presence of superstructure load subjected to vehicle collisions. The influence of superstructure axial load and the top boundary conditions on the pier impact responses were evaluated by developing different simplified pier models in the forms of single columns under equivalent axial load, and the pier-bent model (with multi-columns) in the presence of the superstructure equivalent mass. The importance of the stress initialization analysis phase to reach an equilibrium state of the bridge under the bridge self-weight prior to the transient impact loading phase was revealed. More reasonable results were captured from the pier-bent model rather than those of single piers. Moreover, a parametric study in assessing the influences of different parameters including reinforcement ratios, UHPFRC strength, the thickness of UHPFRC jacket, and the impact velocity was carried out. The thickness of UHPFRC was realized as the most effective factor in the impact resistance of piers rather than others when the impact velocity was rather low. 
In spite of the studies above focused on the impact force and global deformation of piers, the damage mechanisms and failure behaviors (including both local and global failures) of RC bridge piers were evaluated by several research works. Different damage states and failure mechanisms of $\mathrm{RC}$ bridge piers under a truck collision (with a weight of $66 \mathrm{kN}$, a velocity of $31.3 \mathrm{~m} / \mathrm{s}$, and an impact angle of $20^{\circ}$ ) was numerically evaluated by Agrawal et al. [35] as shown in Fig. 6. According to this classification, the pier suffered spalling damages in the concrete cover immediately after the onset of collision. Afterwards, with progressing the damages to the concrete core, the pier endured the rebar severance, breakage at the impact level, concrete erosion at the footing, and the formation of plastic hinges at both top and bottom end of the pier, respectively.

Auyeung and Alipour [36] numerically evaluated the failure behaviors of $\mathrm{RC}$ bridge piers by varying vehicle mass, velocity, pier diameter, and transverse reinforcement. Figure $7 \mathrm{a}-\mathrm{c}$ illustrates different example failure modes of bridge columns such as pure flexure, combined shear-flexure, and pure shear, respectively. While the pier diameter governed the global failure modes, the levels of local failure modes were extremely sensitive to transverse reinforcements. Thereafter, Auyeung et al. [43] proposed a damage index based on the structural characteristics of the bridge pier and the kinetic energy of colliding vehicles to investigate different performance levels of the piers responses under the vehicle collisions. From a parametric study, the vehicle impact velocity was recognized as the most effective loading parameter on the impact and the pier shear forces.

Since the transferring time of shear forces due to applying impact loads arising from vehicle collisions are very short, recognizing the local shear failure mechanisms and the effectiveness of some key dynamic factors such as the pier

Fig. 6 Different damage behaviors of RC piers under vehicle collision [35]

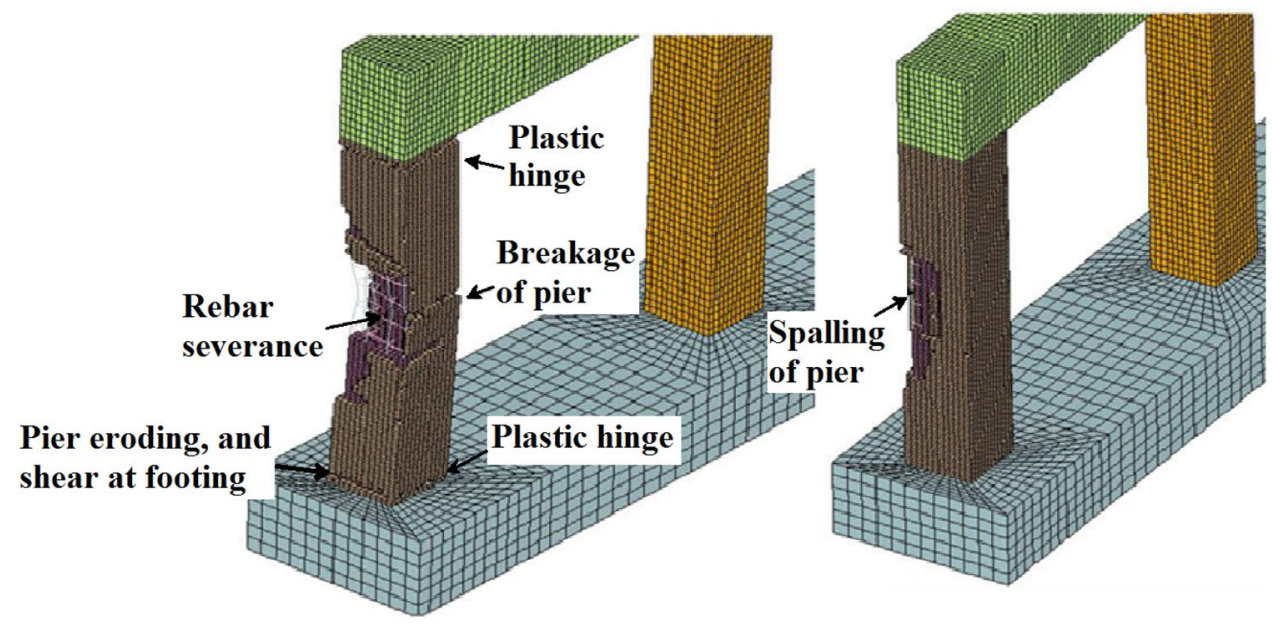

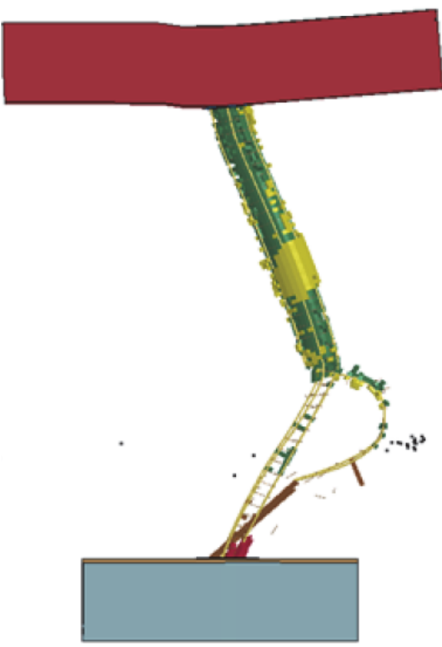

(a) $\mathrm{D}=0.6 \mathrm{~m}$

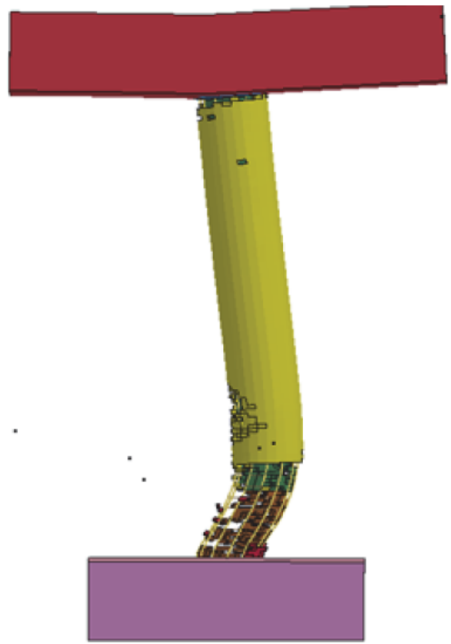

(b) $\mathrm{D}=1.2 \mathrm{~m}$

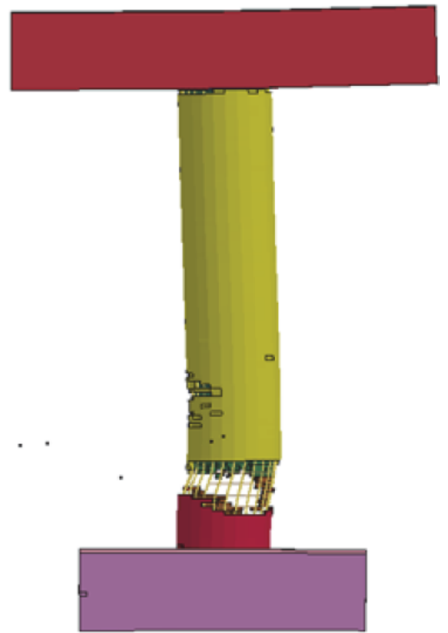

(c) $\mathrm{D}=1.5 \mathrm{~m}$

Fig. 7 Failures of bridge piers with different diameters $(D)$ under vehicle collision [36] 
inertia on the impact responses is very necessary from the design point of view. However, omitting the damage states which are profoundly dependent on the severity of impact loadings and the dynamic shear capacity of RC piers, is a very notable gap of the current design codes. Hence, several attempts have been carried out by the previous works to present some efficient design frameworks considering the shear failure mechanisms of RC piers under vehicles.

As an improvement in the existing methodologies, Sharma et al. [48] proposed an approach to estimate the shear force capacities of RC bridge piers subjected to different vehicle collisions for different damage states and performance levels as shown in Fig. 8. Table 2 presents the damage states in the corresponding performance levels of RC columns under vehicle collision. It was found that the dynamic shear force capacities estimated by the proposed method were more than those calculated by ACI-318 [77]. In addition, compared to the assumption by Tsang and Lam [40] in which the time required to full contact was larger than the duration of shear wave velocity, while it was revealed by Sharma et al. [48] that these durations were almost similar. Afterwards, the fragility of RC columns was assessed by Sharma et al. [29] using a proposed probabilistic method based on the shear capacity of columns. Shear capacities of
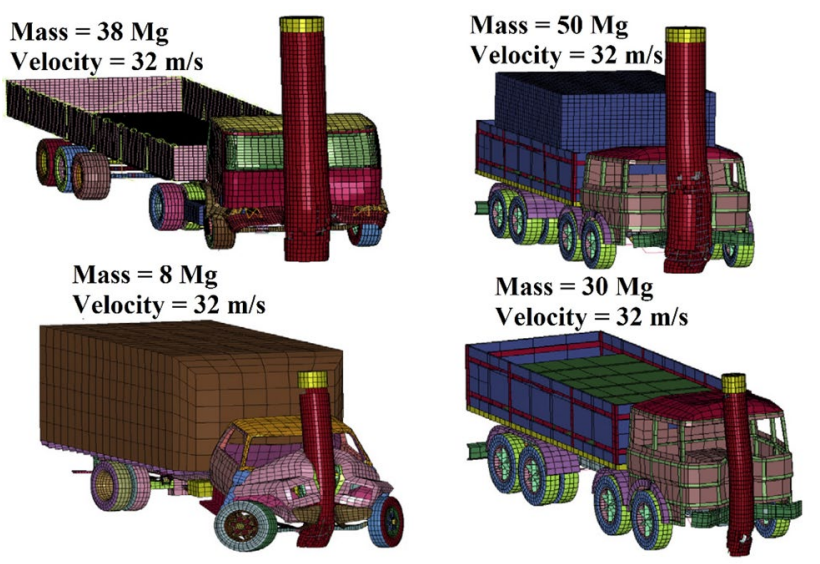

Fig. 8 FE simulation of different vehicle collisions with RC columns with shear failures [48]
RC columns were modeled based on the performance levels to use in a probabilistic assessment by Sharma et al. [50] in terms of different loading and structural uncertainties.

Do et al. [24] investigated the impact responses and failure behaviors of RC bridge columns subjected to vehicle collision using FE simulations in LS-DYNA. While the initial peak impact force was profoundly affected by the engine, the following peaks were more sensitive to the total mass of the vehicle (mostly contains cargo weight). Also, it was revealed that the mass of the engine has a key role in the determination of the pier failure modes and the value of the impact force. In addition, the influence of the pier axial load on the peak impact forces and the failure behaviors was evaluated through different pier-superstructure interaction models. In a mutual action, the substantial positive influences of impact forces on the axial force of the pier were concluded. From a series of the FE simulations of vehicle-pier collisions, various failure behaviors were observed for the piers including flexural failure, shear failure, and punching shear damage which successfully represented the numerical models of those observed in real impact events given in [78] as shown in Fig. 9a-c. Furthermore, two catastrophic flexural and shear failures of bridge columns at the mid-height leading to the collapse of bridge piers, are illustrated in Fig. 10a, b, respectively [78].

Similar to the conclusion of the study done by Do et al. [24], the dependency of the highest peak impact force on the truck's engine block was also concluded by Cao et al. [31] from a series of FE simulations of a heavy truck collision with bridge piers. However, the catastrophic pier failure was observed during the secondary impact of the truck trailer. In addition, a simplified impact loading function (i.e., the impact loading profile) as given in Eq. (1) based on the FE simulation data of colliding truck weight, velocity, and impacted pier cross-sectional dimensions was proposed by Cao et al. [32] to use in the design of bridge piers against the collision of heavy trucks. Then, the performance levels of different bridge piers under the proposed pulse model were evaluated by Cao et al. [33]. The proposed impact pulse model by Cao et al. [32] and the application heights of the pulse model are shown in Fig. 11a, b. This model includes

Table 2 Performance levels of RC columns subjected to vehicle collision [48]

\begin{tabular}{llll}
\hline Damage level & Damage description & $\begin{array}{l}\text { Performance } \\
\text { level }\end{array}$ & Performance level description \\
\hline D1 & Insignificant damage & P1 & $\begin{array}{l}\text { Fully operational with no damage } \\
\text { D2 }\end{array}$ \\
Minor spalling of concrete, yielding of longitudinal steel & P2 & Operational structure with damage \\
& Significant cracking of concrete, Spiral and longitudinal bar & P3 & Total collapse of the structure \\
D4 & $\quad$ exposed, buckling of bars & & \\
\hline
\end{tabular}




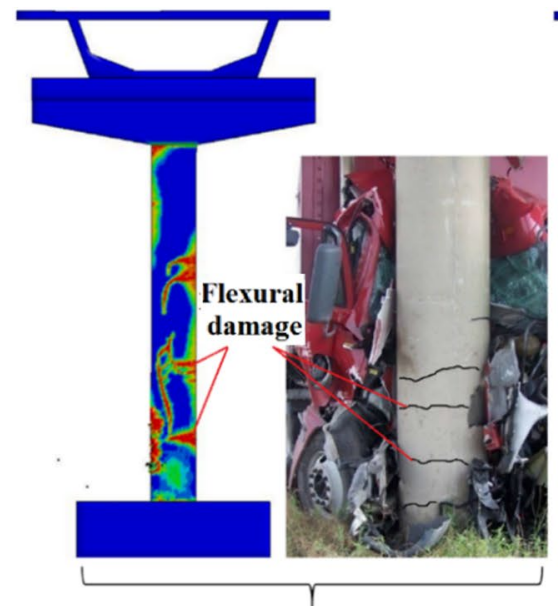

(a) Flexural failure

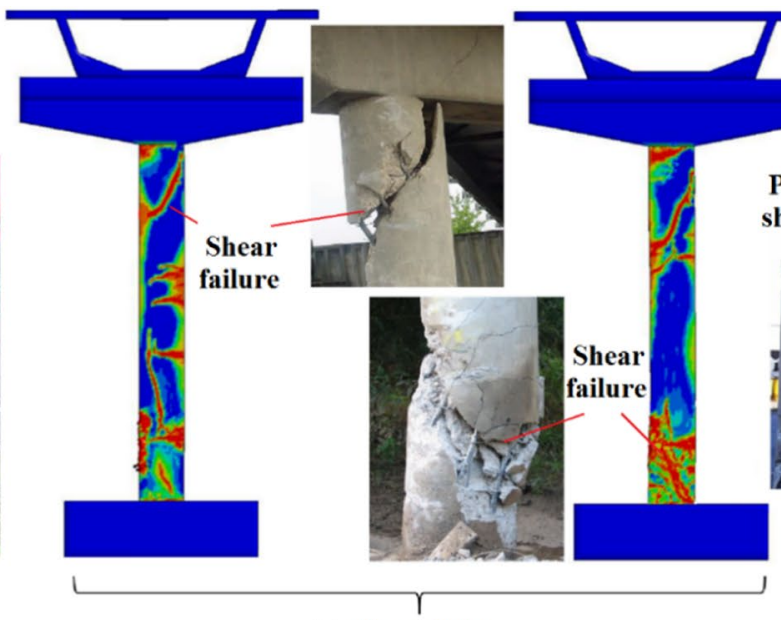

(b) Shear failure

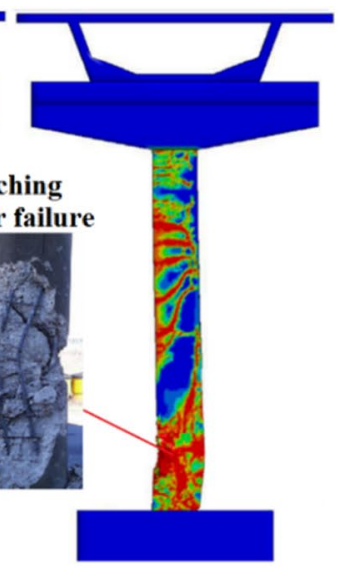

(c) Punching shear failure

Fig. 9 Different failure behaviors of RC bridge piers under vehicle collision obtained FE simulations done by Do et al. [24] compared to those observed in real events [78]

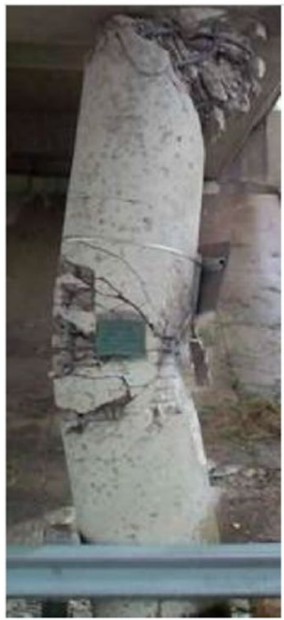

(a) Flexural failure

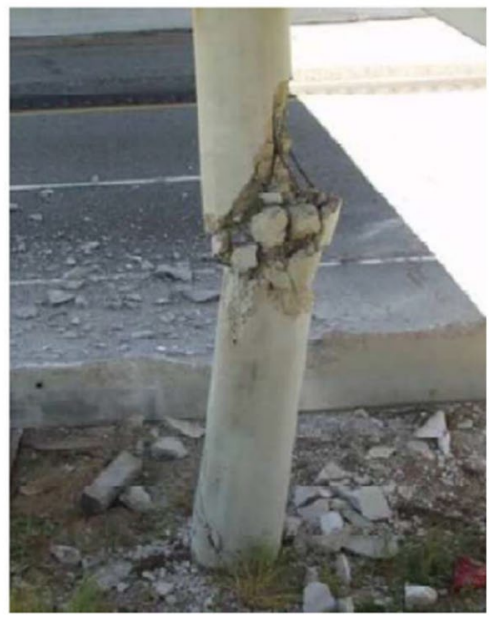

(b) Shear failure

Fig. 10 Typical failures occurred in bridge columns at the mid-height under vehicle collisions [78]

three pulses generated due to the impacts of the bumper (Pulse ${ }^{1}$ ), engine $\left(\right.$ Pulse $\left.^{2}\right)$, and trailer $\left(\right.$ Pulse $\left.^{3}\right)$.

$F_{i}=f\left\{\alpha(V)^{\beta}(W)^{\gamma}\left(\frac{b}{900}\right)^{\varepsilon}\right\}$

where $F_{i}$ denotes the peak force. $\alpha, \beta, \gamma$, and $\varepsilon$ are regression parameters. $V$ and $W$ are the truck impact velocity $(\mathrm{km} / \mathrm{h})$ and weight $(\mathrm{kN}) . b$ denotes the pier width $(\mathrm{mm})$.

Afterwards, Do et al. [50] numerically studied the profile of impact forces from pier-vehicle collisions with respect to various structural- and loading-related parameters. Compared to the impact loading model proposed by Cao et al.

[32], a simplified impact force model was proposed with considering the pier shear capacity as illustrated in Fig. 12a, b. According to this model, the first impact phase $\left(P_{1}\right)$ is dependent on the length between the bumper and the engine, the truck velocity, the column width. During this phase, the peak impact force $(P I F)$ (i.e., $F_{l}$ ) can be calculated using the engine's mass and the impact velocity as given in Eq. (2). The pier endures a punching shear failure when $P I F$ reaches the maximum dynamic shear capacity $\left(P_{d y n}^{\max }\right)$ as calculated by Eq. (3). The second phase $\left(P_{2}\right)$ was taken equal to 1290 $\mathrm{kN}$.

$F_{1}(\mathrm{kN})=969.3 \sqrt{0.5 m_{e} V^{2}}-7345.9 \leq P_{d y n}^{\max }(16.7 \mathrm{~m} / \mathrm{s}<V<40 \mathrm{~m} / \mathrm{s})$

where $m_{e}$ is the mass of the engine (ton), and $V$ is the truck impact velocity.

$P_{d y n}^{\max }=2\left(D I F_{c} \times V_{c}+D I F_{s} \times V_{s}\right)+\sum m a$

where $D I F_{c}$ and $D I F_{s}$ are the dynamic increase factors of the concrete and steel material strength in the diagonal section, respectively. $V_{c}$ and $V_{s}$ are the contribution of the concrete and the steel reinforcement to resist the shear force, respectively. $m$ and $a$ are the mass and acceleration of the shear plug, respectively.

From the vast majority of pier-vehicle collision studies as summarized in Table 3, the significant influences of the impacting vehicle characteristics such as vehicle type (including the variability of the bow configuration), impact velocity, and vehicle weight (including the mass of both engine and cargo portions) were concluded. However, the design collision force provided by AASHTO specifications does not consider the effects of dynamic vehicle-pier 
(a)

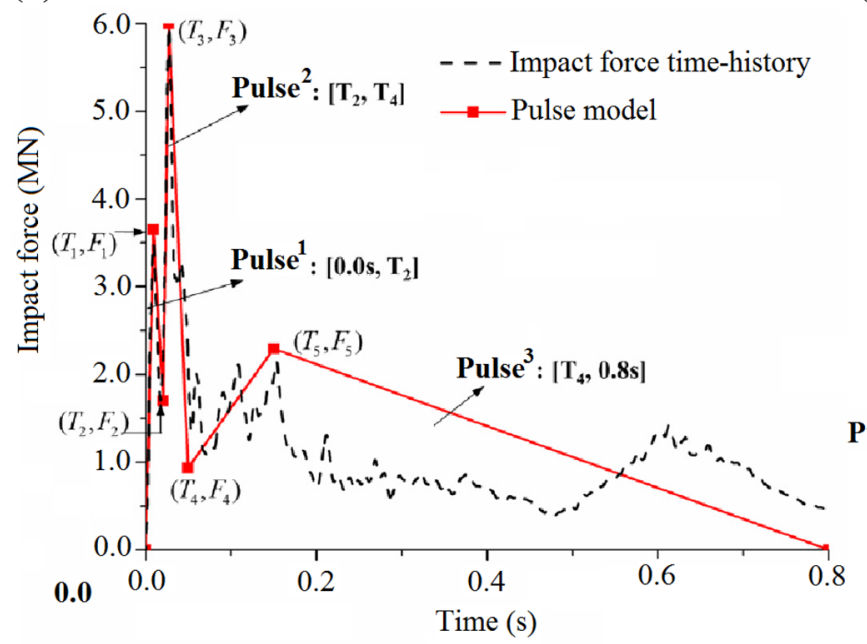

(b)

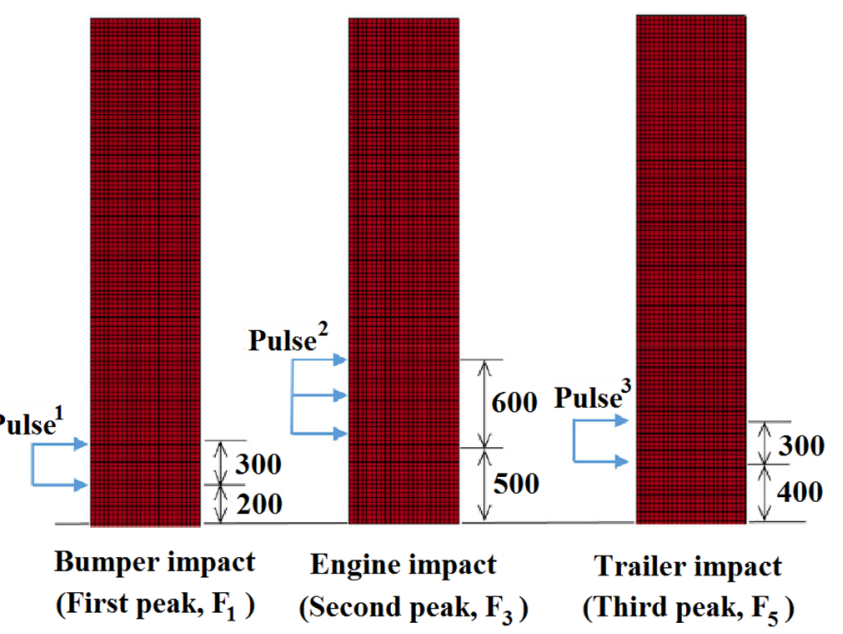

Fig. 11 a The impact pulse model proposed by Cao et al. [32], b application heights of the pulses

(a)

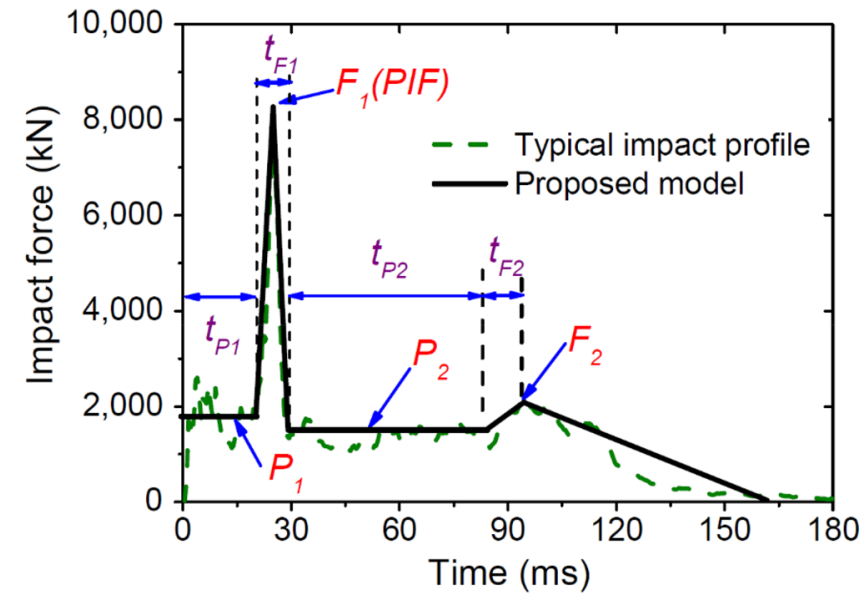

(b)

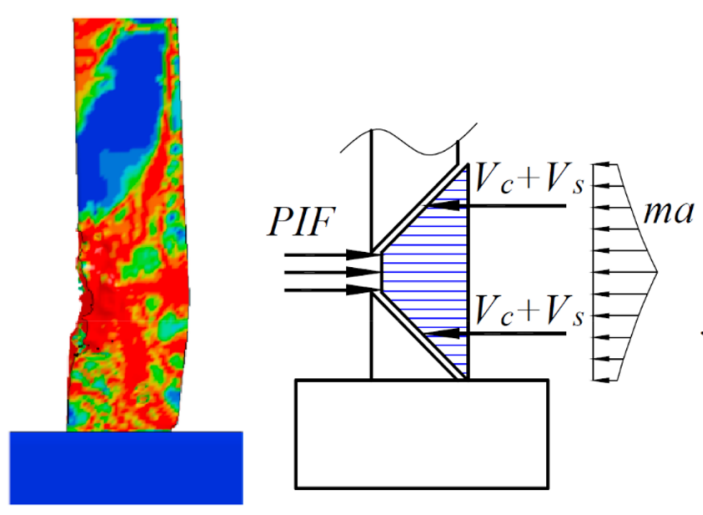

Punching shear failure

Fig. 12 a Simplified model of the impact force, $\mathbf{b}$ the mechanism of punching shear failure [50]

interactions, impact velocity, vehicle weight and characteristics. From an FE numerical study of truck collision with different bridge piers by El-Tawil et al. [27], it was concluded that dynamic peak impact forces could be larger than those predicted by AASSHTO-LRFD [10] and design approach proposed by this design code could be unconservative.

Compared to the extensive investigation on the effects of various structural parameters, the influences of the axial load parameter have not been comprehensively explored. Besides, most of the previously concluded the positive influences of this parameter on the impact resistance of bridge piers when it was in its service levels. Therefore, more attempts are needed to explore the sensitivity levels of the impact responses of bridge piers to the axial load parameter in future works.

According to the conclusions of several works investigating precast concrete segmental bridge columns (PCSBC), such types of columns can provide more ductility and suffer fewer damages under lateral impact loads compared to conventional RC bridge piers $[46,51,79,80]$. The performance of precast segmental columns under vehicle collisions was numerically assessed by Do et al. [49] varying in prestressing level, number of segments, concrete strength, and vehicle velocity. It was found that the number of segments and initial prestressing level had marginal influences on the impact force, while they significantly affected the residual displacements and the damage behaviors. Moreover, 
Table 3 Summary of the influences of various parameters on the impact responses of RC bridge piers to vehicle collisions

\begin{tabular}{|c|c|c|c|}
\hline Study & Analysis & Parameter & Effectiveness \\
\hline \multirow[t]{4}{*}{ Zhou et al. [41] } & \multirow[t]{4}{*}{ Numerical } & Impact velocity & Substantial positive on the peak impact force \\
\hline & & Impact mass & \\
\hline & & Concrete strength & Marginal negative on the pier global deformations \\
\hline & & Reinforcements strength & Substantial negative on the pier global deformations \\
\hline \multirow[t]{9}{*}{ Abdelkarim and ElGawady [34] } & \multirow[t]{9}{*}{ Numerical } & Concrete strength & No effect on the peak impact force \\
\hline & & Reinforcement ratio & Positive on the peak impact force \\
\hline & & Column cross-sectional dimensions & Positive on the peak impact force \\
\hline & & Axial load & \\
\hline & & Impact velocity & \\
\hline & & Impact weight & \\
\hline & & Material strain rate & \\
\hline & & Pier boundary condition & No effect on the peak impact force \\
\hline & & Depth of soil surrounding pier substructure & \\
\hline \multirow[t]{3}{*}{ Chen et al. [37] } & \multirow[t]{3}{*}{ Analytical } & impact velocity & Substantial positive on the peak impact force \\
\hline & & Pier cross-sectional dimensions & \\
\hline & & Pier material properties & \\
\hline \multirow[t]{2}{*}{ Chen et al. [39] } & \multirow[t]{2}{*}{ Experimental } & Impact velocity & Significant positive on the peak impact force \\
\hline & & Impact mass & \\
\hline \multirow[t]{5}{*}{ Chen et al. [45] } & \multirow[t]{13}{*}{ Numerical } & Pier cross-sectional shape and dimensions & Marginal effects on the impact force \\
\hline & & Impact velocity & Significant effects on the first peak impact force \\
\hline & & Cargo weight & $\begin{array}{l}\text { Significant effect on the following peaks of impact } \\
\text { force }\end{array}$ \\
\hline & & Impact position & Significant positive on the peak impact force \\
\hline & & Vehicle type & \\
\hline \multirow[t]{3}{*}{ Yi et al. [47] } & & Cross-sectional shape & $\begin{array}{l}\text { More severe damages and displacements for Round- } \\
\text { shape piers than square-shape }\end{array}$ \\
\hline & & Axial load & No influence on impact resistance \\
\hline & & Concrete strength & \\
\hline \multirow[t]{5}{*}{ Fan et al. [28] } & & Axial load & $\begin{array}{l}\text { Positive in the service level for small deformations; } \\
\text { Negative for large deformations }\end{array}$ \\
\hline & & Reinforcement ratios & Marginal positive on the pier resistance \\
\hline & & UHPFRC strength & \\
\hline & & UHPFRC thickness & $\begin{array}{l}\text { Substantial positive on the pier lateral impact } \\
\text { resistance and axial load capacity for low-velocity } \\
\text { impacts }\end{array}$ \\
\hline & & Impact velocity & Significant positive on the pier damage level \\
\hline \multirow[t]{4}{*}{ Auyeung and Alipour [36] } & \multirow[t]{4}{*}{ Numerical } & Impact mass & Substantial positive on the peak impact force \\
\hline & & Impact velocity & \\
\hline & & Pier diameter & $\begin{array}{l}\text { Substantial negative on the pier global failure modes } \\
\text { (i.e., governed the global failures) }\end{array}$ \\
\hline & & Transverse reinforcement & $\begin{array}{l}\text { Substantial negative on the pier local failure modes } \\
\text { (i.e., governed the local failures) }\end{array}$ \\
\hline Auyeung et al. [43] & Numerical & Impact velocity & $\begin{array}{l}\text { Significant positive on the impact and the pier shear } \\
\text { forces }\end{array}$ \\
\hline \multirow[t]{2}{*}{ Do et al. [24] } & \multirow[t]{2}{*}{ Numerical } & Vehicle engine's mass & $\begin{array}{l}\text { Significant positive on the peak impact force, shear } \\
\text { forces, and moment }\end{array}$ \\
\hline & & Vehicle velocity & Significant positive on the peak impact force \\
\hline \multirow[t]{2}{*}{ Cao et al. [31] } & \multirow[t]{2}{*}{ Numerical } & Vehicle engine's mass & Significant positive on the highest peak impact force \\
\hline & & Vehicle trailer's mass & $\begin{array}{l}\text { Significant positive on the following peaks of impact } \\
\text { force, and damage levels }\end{array}$ \\
\hline
\end{tabular}


it was revealed that the impact velocity has not always absolute positive influences on the impact force of segmental columns. In line with this study, impact behaviors of two different bridge piers including RC pier, precast modular pier were numerically evaluated by Chung et al. [46] subjected to impact loading functions derived from a series of vehicle-pier collision simulations. Larger displacement and stresses were obtained in precast pier than those of RC piers under the same peak dynamic loading. Afterwards, Do et al. [80] carried out a comparative study between the impact performance of precast concrete segmental bridge columns (PCSBC) and monolithic bridge columns, better flexural and shear performances were obtained for PCSBC due to the existence of shear slippage and joint rocking between concrete segments. In addition, PCSBC columns suffered localized shear and compression damages limited to the impacted segments compared to the global flexural and shear damages observed in the monolithic columns. With the intent of reducing the stresses and relative displacements between the segments of the column under lateral impact loads, Zhang et al. [79] utilized a new shear design with smoothed curvature.

\subsection{Bridge Piers Subjected to Vessel Collisions}

Bridge piers spanning across the navigable coastal channels are potentially at the risk of vessel collisions that can cause severe damages or even collapse of such structures [81-83]. Based on a report given by AASHTO [7], during a time period from 1960 to 2002, vessel collisions caused the collapse of 31 bridges and 342 fatalities. Figure 13 shows the collapse of several bridges due to vessel collisions. Several design codes for bridges [7-9] include the vessel collision loads on the basis of static analysis methods considering the type of striking vessel and waterways. However, the provisions provided by these guidelines are not able to accurately estimate the vessel collision loads due to omitting dynamic characteristics, and the geometry of both striking vessels and stuck bridge structures.
As a prominent and famous experimental study, Consolazio et al. [84] conducted a series of full-scale barge collision tests on the old piers of St. George Island Bridge. Many open-access technical reports were published based on the information from these experimental tests capturing novel insights in various aspects of the vessel-bridge collision event [85-92]. However, conducting full-scale experimental tests of vessel collisions with bridges requires special strategic plans and notable financial resources. Hence, analytical and numerical approaches using high fidelity computer software can be considered as a proper alternative to estimate the responses of both vessels and impacted structures, accurately and reasonably.

Generally, the dynamic analysis of vessel-bridge pier collision can be categorized into three techniques as follows:

- High-resolution finite element (FE) technique consists of a multiple-degree-of-freedom (MDOF) model of vessel versus an MDOF model of bridge pier as shown in Fig. 14a.

- Medium-resolution technique consists of a single-degreeof-freedom (SDOF) model of vessel versus MDOF model of a bridge pier as shown in Fig. 14b.

- The low-resolution technique consists of an SDOF model of a vessel versus an SDOF model of a bridge pier as shown in Fig. 14c.

In the first technique, the dynamic impact loads, the nonlinear dynamic responses and failure behaviors of both bridge structure and impacting vessel such as the crush deformations are quantified considering detailed collision mechanics and nonlinear interactions between the highresolution FE models of impacting vessel and bridge pier. However, adopting such techniques will not be appropriate for design applications because they require significant computational costs and resources. In the second technique (i.e., medium-resolution), the stiffness (load-deformation) of the vessel bow is simplified using a nonlinear discrete element in the vessel SDOF system. Although this technique is not able to obtain the vessel crush behaviors, it can be properly

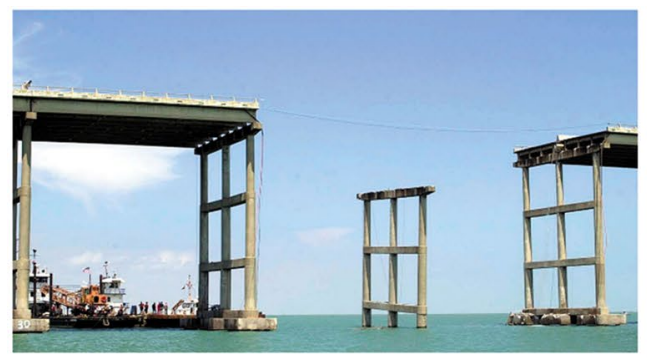

(a) Queen Isabella Causeway Bridge [81]

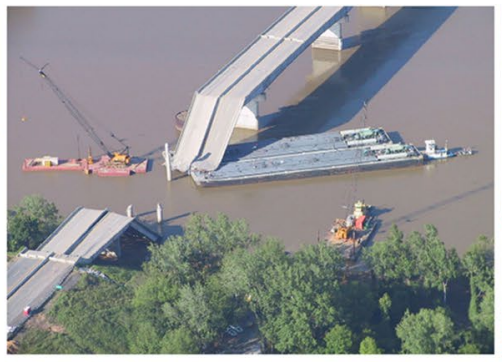

(b) I-40 Bridge [82]

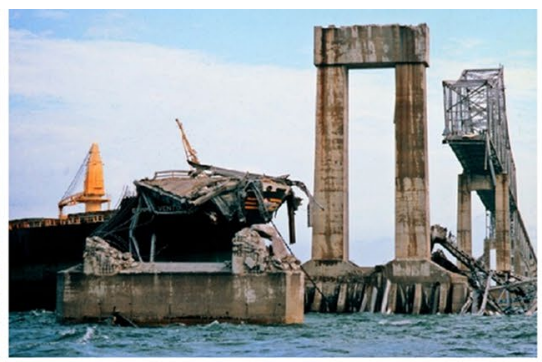

(c) Sunshine Skyway Bridge [83]

Fig. 13 The collapse of several bridges in the USA due to vessel collisions 


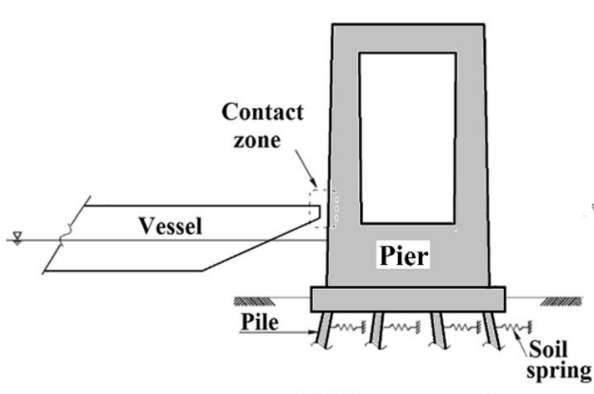

(a) High-resolution

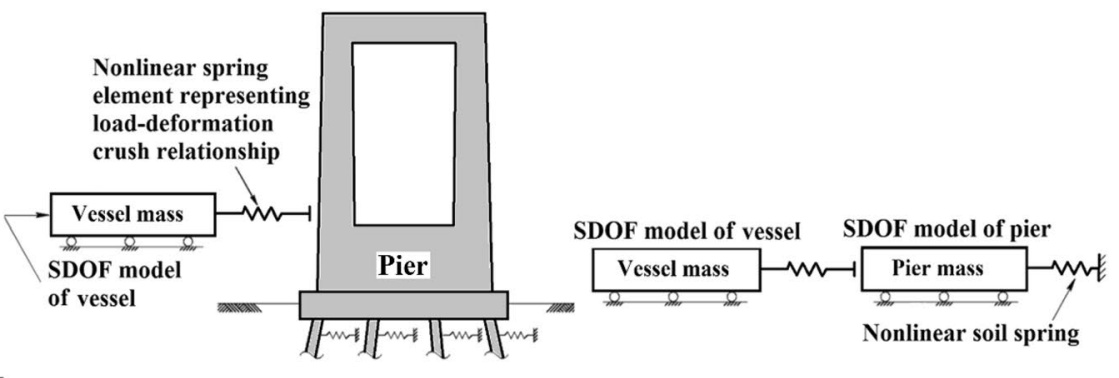

(b) Medium-resolution (c) Low-resolution

Fig. 14 Different dynamic analysis techniques of vessel-pier collision [93]

used for design intents due to considering the high-resolution model and all structural characteristics of the impacted pier. Besides, low-resolution techniques representing the simplified models of vessel-pier collisions are particularly utilized to predict the dynamic impact loads as the preliminary stage of a design process.

There exist various analytical approaches in the literature simplifying the models of the striking vessel and impacted bridge. Consolazio and Cowan [94] proposed a coupled vessel impact analysis (CVIA) method in which an SDOF vessel model collides with an MDOF pier model (i.e., mediumresolution technique). In this technique, various loading and structural-related parameters of vessel-pier collision system including vessel bow stiffness, vessel mass, impact velocity, impact angle, pier stiffness, pier mass, pier geometry, and soil conditions were taken into account to capture time history results of impact force, bridge displacements, and internal structural forces generated in bridge pier. The stiffness of vessel bow modeled with a nonlinear spring represents the load-deformation crush relationships captured from the high-resolution analysis [95]. Thereafter, the proposed coupled CVIA used to analysis the dynamic responses of an equivalent one-pier, two-span (OPTS) simplified bridge model proposed by Consolazio and Davidson [96] in which the effects and characteristics of adjacent piers and spans were considered using a series of equivalent translational and rotational springs attached to a lumped mass of adjusted piers and spans as shown in Fig. 15. The capability of this model was concluded to successfully predict the pier impact responses considering the dynamic amplification characteristics along with a significant reduction in the analysis time. Fan et al. [97] proposed a nonlinear dynamic macro-element model of bridge pier to quantify the pier demand subjected to ship collisions as shown in Fig. 16. In this model, the
Fig. 15 Analytical model for bridge-ship collisions based on the proposed macro-element by Consolazio and Cowan [96]

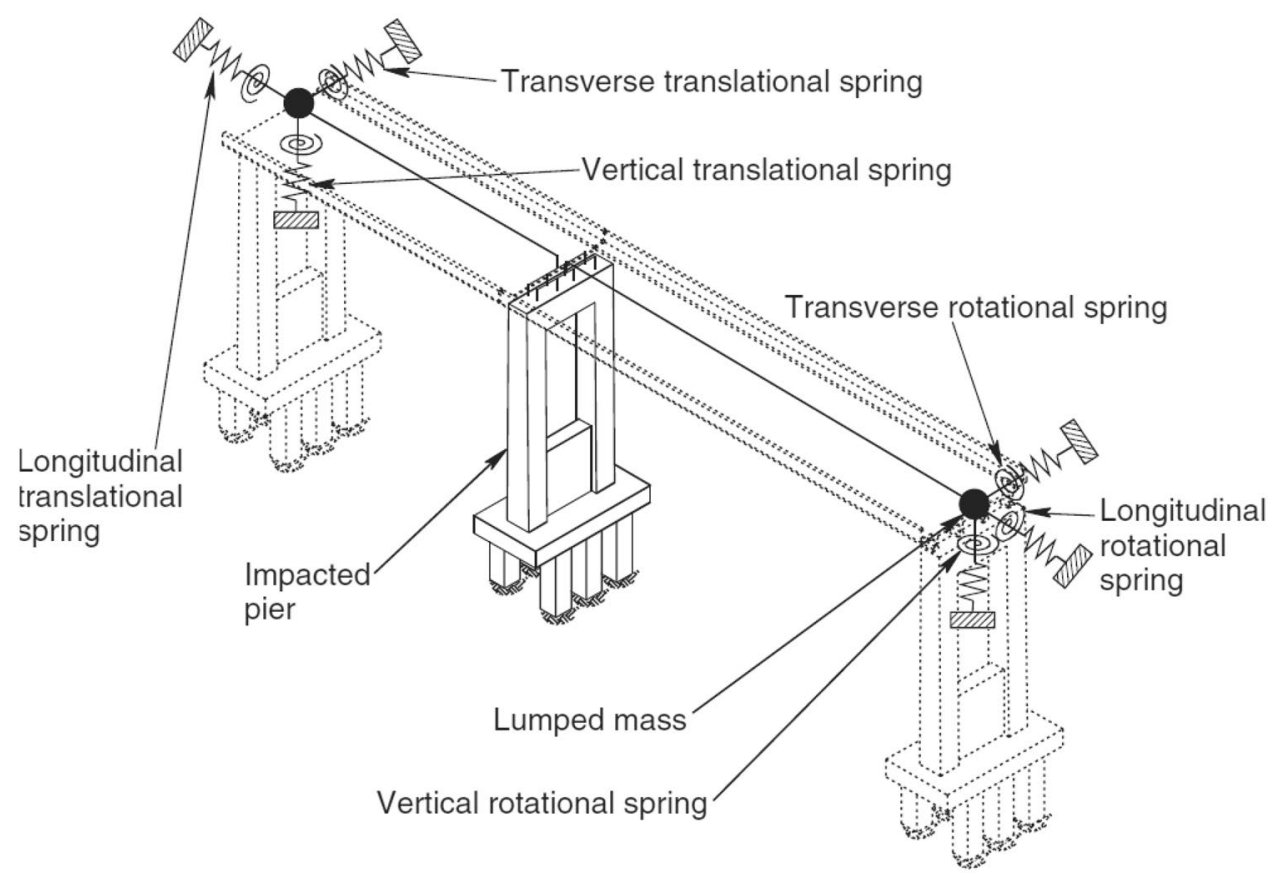



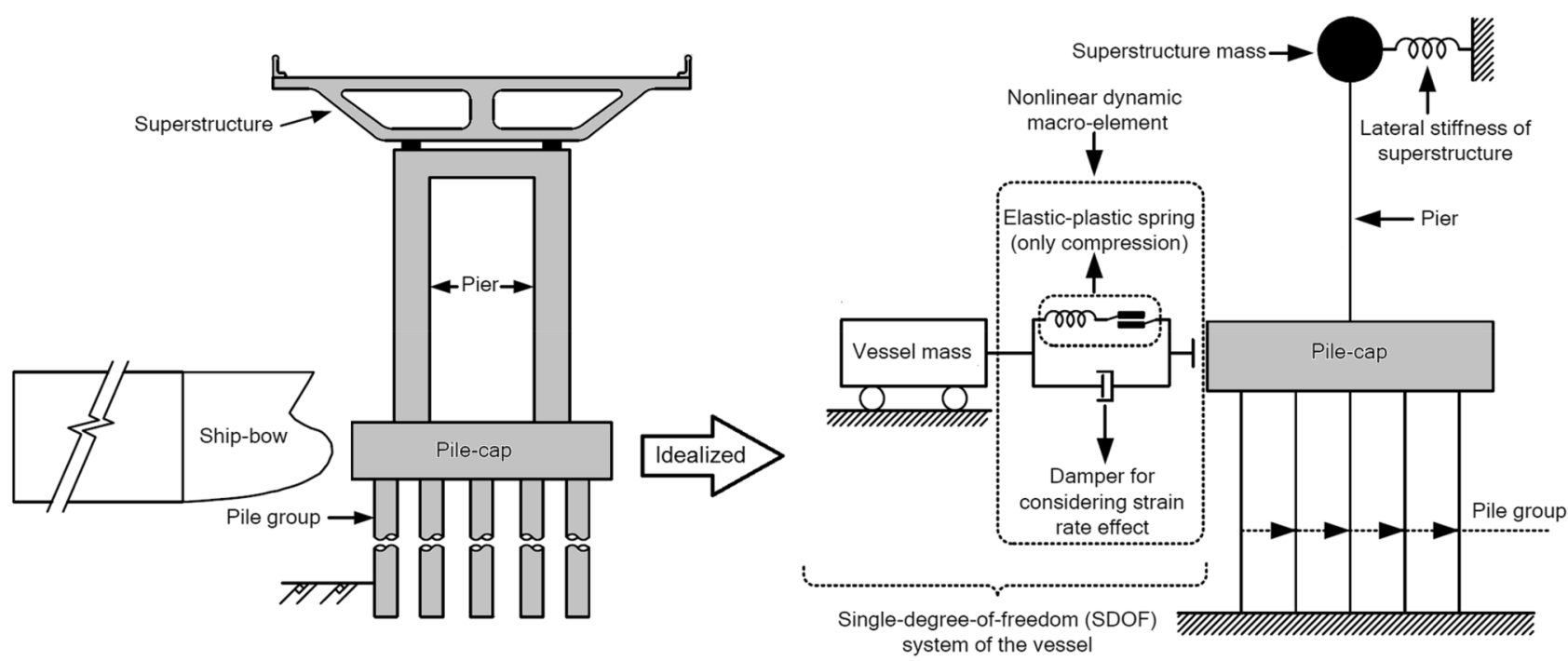

Fig. 16 Macro-element model of bridge pier using spring and lumped mass elements [97]

crush behavior of ship bow with considering the strain rate effects was modeled using the combination of an elastic-plastic spring and a dashpot element attached to each other in parallel. The calculated results from the proposed method were agreed well with those from high-resolution analysis. Moreover, it was revealed that the design impact forces predicted by the current design codes can be underestimated due to neglecting the dynamic amplification factors such as the material strain rate effects.

A vast majority of vessel-bridge collision studies focused on investigating the force-deformation results of vessels considering the shape and size of the impacted pier under low to medium-rate [94, 95, 98-101], and high-rate impacts $[102,103]$. Besides, many attempts were carried out to evaluate the structural responses of bridge piers using simplified analytical methods $[62,65,96,104,105]$, and FE high-resolution techniques $[52,54,59,67,106]$. In addition, several approaches were proposed to analyze the impact loads and bridge dynamic demands using shock spectrum analysis [104, 107-109], structural reliability analysis [55, 63, $110-114]$, and equivalent static analysis $[115,116]$ methods. Table 4 presents a summary of vessel-pier collisions with regard to the influences of various parameters.

In Table 4, it can be found that the impact forces and responses are affected not only by loading-related parameters including vessel mass, velocity, weight, bow configurations (stiffness-related), but also by structural-related parameters including the pier inertia, axial load ratio (superstructure inertia-related), geometry, and soil-structure interaction behavior. However, the force-deformation relationships provided by the current design codes such as AASHTO have not taken into account the key dynamic factors of both vessel and impact pier such as the strain rate effects of materials, geometry, shape, and size parameters. Hence, these deficiencies existing in the guidelines may lead to unconservative and inaccurate impact loads and structural responses. In addition, although the effectiveness of the pier superstructure inertia has been considered by several vessel-pier collision studies, except very limited works in the literature [52], the sensitivity of the impact resistances of bridge piers to axial load parameter has not been rigorously investigated.

The significant effects of the different boundary conditions of impacted bridges at the top affected by the inertia of overlaying superstructures $[54,66]$ and at the bottom surrounded by soil layer [53, 61, 64, 116-119] were explored in the literature. The substantial influences of bridge superstructure on the impact responses and failure behaviors of the impacted pier especially on the location of plastic hinge formed in the pier columns were concluded by Gholipour et al. [52]. Figure 17 illustrates the influence of the bridge superstructure on the failure modes of the impacted pier. It is observed that the pier indicates different characteristics for the formed plastic hinges $(P H)$ including their locations and the relative curvatures $(a)$. Based on a study done by Davidson et al. [66], the amplification dynamic effects of bridge superstructures during a vessel collision event can be categorized into: (1) inertial resistance of superstructure amplification which is mobilized shortly after the onset of impact loading and causes maximum shear forces in bridge pier and (2) superstructure momentum driven-sway amplification due to increasing the velocity at the pier top which leads to producing maximum bending moments in the pier.

Despite many previous studies considering the effects of dynamic characteristics of both vessel and pier aforementioned above, the material nonlinearity and structural damages have been taken into account in predicting impact 
Table 4 Summary of the influences of various parameters on the impact responses of RC bridge piers to vessel collision

\begin{tabular}{|c|c|c|c|}
\hline Study & Analysis & Parameter & Effectiveness \\
\hline \multirow[t]{5}{*}{ Consolazio and Cowan [94] } & \multirow[t]{5}{*}{ Numerical } & Barge mass & $\begin{array}{l}\text { Marginal positive influence on the pier } \\
\text { demand and the peak impact force; } \\
\text { Significant positive effects on the impact } \\
\text { duration }\end{array}$ \\
\hline & & Impact angle & $\begin{array}{l}\text { Marginal influence on the impact force; } \\
\text { Significant negative effects on the pier } \\
\text { deflection }\end{array}$ \\
\hline & & Pier stiffness & \multirow{2}{*}{$\begin{array}{l}\text { Marginal positive on the impact force and } \\
\text { the pier resistance }\end{array}$} \\
\hline & & Pier mass & \\
\hline & & Pier geometry & $\begin{array}{l}\text { Marginal positive on the impact force } \\
\text { Significant effects on the pier deflection } \\
\text { (Greater impact resistance by circular- } \\
\text { shaped columns than those of square- } \\
\text { shaped columns) }\end{array}$ \\
\hline Consolazio et al. [95] & Numerical & Pier geometry & $\begin{array}{l}\text { Higher impact forces for Round-faced col- } \\
\text { umns than those for Flat-faced columns }\end{array}$ \\
\hline \multirow[t]{2}{*}{ Consolazio and Cowan [98] } & \multirow[t]{2}{*}{ Numerical } & Pier width/diameter & Marginal influence on the impact force \\
\hline & & Pier geometry & $\begin{array}{l}\text { Significant effects on the impact forces } \\
\text { (higher forces for Flat-faced columns } \\
\text { than Round-faced columns) }\end{array}$ \\
\hline Yuan and Harik [99] & Numerical and Analytical & $\begin{array}{l}\text { Pier geometry } \\
\text { Pier width/diameter }\end{array}$ & $\begin{array}{l}\text { Significant positive on the peak impact } \\
\text { force of rectangular piers; Marginal posi- } \\
\text { tive on the peak impact force of circular } \\
\text { piers }\end{array}$ \\
\hline Getter and Consolazio [100] & Numerical & Impact angle & $\begin{array}{l}\text { Significant negative on the bow force- } \\
\text { deformation relationship for impact on } \\
\text { wide piers; Similar effectiveness for } \\
\text { impact angles of } 5^{\circ} \text { or more, when piers } \\
\text { have less width }\end{array}$ \\
\hline Fan and Yuan [101] & Numerical & Pile-cap depth & $\begin{array}{l}\text { Important role in quantifying impact } \\
\text { demand of bridge piers }\end{array}$ \\
\hline Kantrales et al. [102] & Experimental and Analytical & Pier geometry & $\begin{array}{l}\text { Larger impact forces were obtained for } \\
\text { flat-faced piers than those for round- } \\
\text { faced piers }\end{array}$ \\
\hline Luperi and Pinto [103] & Numerical & $\begin{array}{l}\text { Pier width/diameter } \\
\text { Pier geometry }\end{array}$ & $\begin{array}{l}\text { More significantly positive on the bow } \\
\text { force-deformation relationships for flat- } \\
\text { faced piers than round-faced-piers }\end{array}$ \\
\hline \multirow[t]{5}{*}{ Wang and Morgenthal [60] } & \multirow[t]{5}{*}{ Numerical and analytical } & Barge mass & $\begin{array}{l}\text { Significant positive on the peak impact } \\
\text { force until } 25 \% \text { loaded barge; Ascending } \\
\text { positive on the pier deflection; Marginal } \\
\text { on the pier moment }\end{array}$ \\
\hline & & Impact velocity & $\begin{array}{l}\text { Significant positive on the peak impact } \\
\text { force and the pier deflection }\end{array}$ \\
\hline & & Height of impact location & $\begin{array}{l}\text { Marginal on the peak impact force; Sig- } \\
\text { nificant positive on the pier deflection }\end{array}$ \\
\hline & & Column height & $\begin{array}{l}\text { Marginal on the peak impact force and the } \\
\text { pier deflection }\end{array}$ \\
\hline & & Diameter of longitudinal reinforcement & $\begin{array}{l}\text { Marginal on the peak impact force; Sig- } \\
\text { nificant negative on the pier deflection }\end{array}$ \\
\hline Fan et al. [65] & Numerical and analytical & Strain rate of steel used for vessel bow & $\begin{array}{l}\text { Significant positive on the impact forces; } \\
\text { Significant negative on the impact dura- } \\
\text { tion }\end{array}$ \\
\hline
\end{tabular}


Table 4 (continued)

\begin{tabular}{|c|c|c|c|}
\hline Study & Analysis & Parameter & Effectiveness \\
\hline \multirow[t]{5}{*}{ Yuan et al. [105] } & \multirow[t]{5}{*}{ Numerical and analytical } & Pier stiffness & $\begin{array}{l}\text { Significant effect on the peak impact } \\
\text { forces; Marginal effect on the mean } \\
\text { impact force }\end{array}$ \\
\hline & & Number of barges in a flotilla & $\begin{array}{l}\text { Marginal effect on the mean impact force; } \\
\text { Positive on the impact duration }\end{array}$ \\
\hline & & Pier geometry & $\begin{array}{l}\text { Larger impact forces produced by square } \\
\text { columns than those by a circular column }\end{array}$ \\
\hline & & Pier width & Significant positive on the impact forces \\
\hline & & Kinetic impact energy & Significant effect on the impact duration \\
\hline \multirow[t]{2}{*}{ Gholipour et al. [52] } & \multirow[t]{2}{*}{ Numerical } & Axial load ratio & $\begin{array}{l}\text { Marginal positive on the peak impact } \\
\text { force; Negative on the length of plastic } \\
\text { hinges; Positive on the column resistance } \\
\text { until a ratio of } 0.5\end{array}$ \\
\hline & & Impact velocity & $\begin{array}{l}\text { Significant positive on the peak impact } \\
\text { forces; Negative on the length of plastic } \\
\text { hinges }\end{array}$ \\
\hline \multirow[t]{2}{*}{ Gholipour et al. [54] } & \multirow[t]{2}{*}{ Numerical } & Superstructure to pier mass ratio & $\begin{array}{l}\text { Significant positive on the peak impact } \\
\text { forces }\end{array}$ \\
\hline & & Height of impact location & $\begin{array}{l}\text { Significant positive on the peak impact } \\
\text { forces and the pier demand for ratios } \\
\text { more than } 1.0\end{array}$ \\
\hline \multirow[t]{3}{*}{ Fan and Yuan [59] } & \multirow[t]{3}{*}{ Numerical } & Pier concrete nonlinearity & $\begin{array}{l}\text { Significant effect on the impact force and } \\
\text { barge crush depth }\end{array}$ \\
\hline & & Impact velocity & $\begin{array}{l}\text { Significant positive on the peak impact } \\
\text { forces and durations }\end{array}$ \\
\hline & & Barge mass & $\begin{array}{l}\text { Marginal effect on the impact force for } \\
\text { high-velocity impacts }\end{array}$ \\
\hline Getter et al. [115] & \multirow[t]{2}{*}{ Numerical and Analytical } & Superstructure inertia & Significant effect on the pier demand \\
\hline Gholipour et al. [53] & & Soil-pier interaction & $\begin{array}{l}\text { Significant effect on the relatively light } \\
\text { piers }\end{array}$ \\
\hline \multirow[t]{5}{*}{ Sha and Hao [57] } & \multirow[t]{5}{*}{ Experimental and Numerical } & Impact velocity & $\begin{array}{l}\text { Significant effect on the peak impact } \\
\text { forces }\end{array}$ \\
\hline & & Vessel mass & Significant effect on the impact durations \\
\hline & & Pier height & Marginal influences on the impact force \\
\hline & & Superstructures mass & \\
\hline & & Height of impact location & \\
\hline \multirow[t]{2}{*}{ Zhang et al. [61] } & \multirow[t]{2}{*}{ Numerical } & Initial kinetic energy of collision & $\begin{array}{l}\text { Significant positive on the pier demand } \\
\text { and the soil deformations }\end{array}$ \\
\hline & & Soil damping surrounding the piles & Negative effect on the pier demand \\
\hline
\end{tabular}

responses and failure behaviors of the impacted piers [52, $55,59,67,120]$. With growing FE computer codes in recent years and feasibility of modeling the nonlinear behaviors of concrete materials considering strain rate effects, several studies were focused on investigating the damage and failure behaviors [23, 52, 57, 59, 62], and progressive collapse [67, $117,121,122]$ bridges under vessel impact loads.

The nonlinear dynamic responses and progressive damage process of a cable-stayed concrete bridge pier were numerically and analytically investigated by Gholipour et al. [120] under ship collision considering the nonlinearity of concrete and steel materials. In addition, the strain rate effects of concrete and steel materials were formulated to use in a proposed two-degree-of-freedom simplified system. It was found that the proposed simplified method could accurately estimate the impact force and pier displacement response compared to those from FE simulations. Moreover, among different damage indices proposed to describe the damage states of the impacted pier, a damage index based on pier deflection was captured more efficient approach than others. Besides, the progressive damage process of the impacted pier from the appearance of minor tensile and flexural cracks, developing shear damages, cross-sectional fracture, and consequently the formation of plastic hinges 


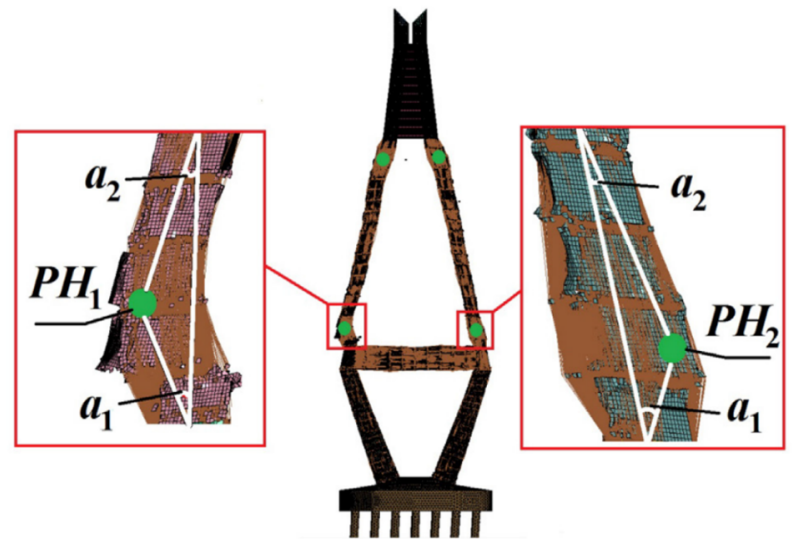

(a) Bridge pier without superstructure

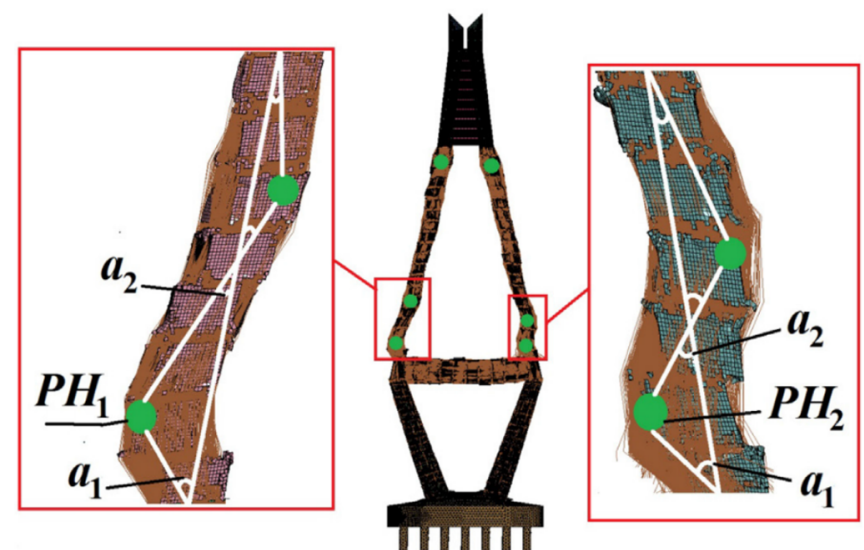

(b) Bridge pier in the presence of the superstructure

Fig. 17 Failure behaviors of the bridge pier with and without the superstructure subjected to ship collision [52]

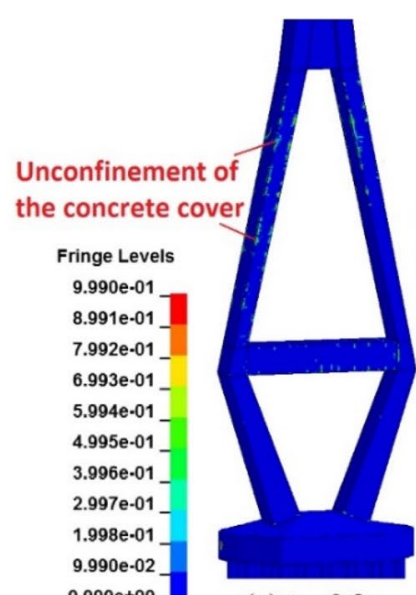

(a) $\mathrm{t}=0.2 \mathrm{~s}$

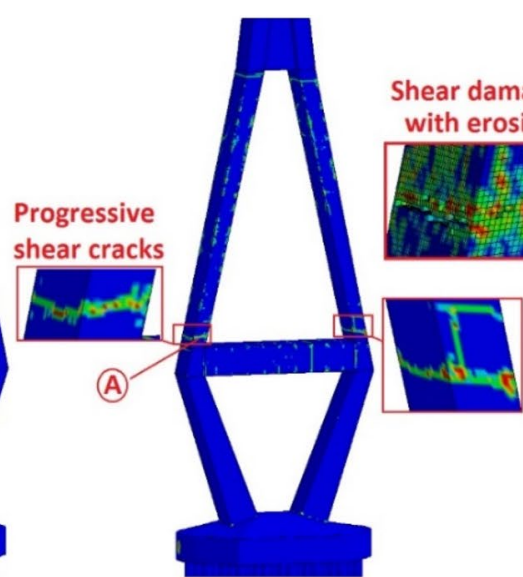

(b) $\mathrm{t}=0.3 \mathrm{~s}$

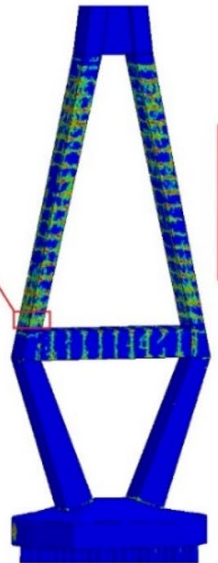

(c) $\mathrm{t}=0.5 \mathrm{~s}$

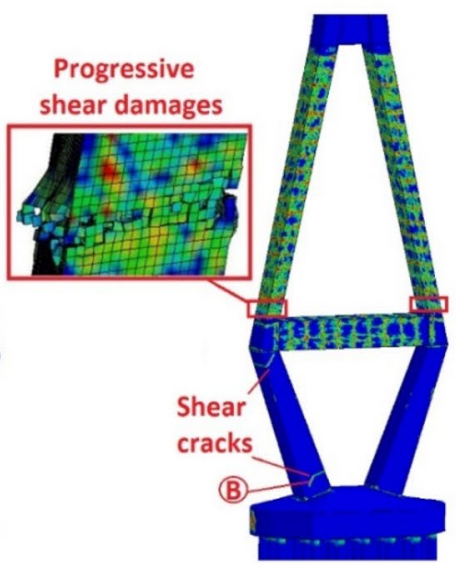

(d) $\mathrm{t}=0.7 \mathrm{~s}$

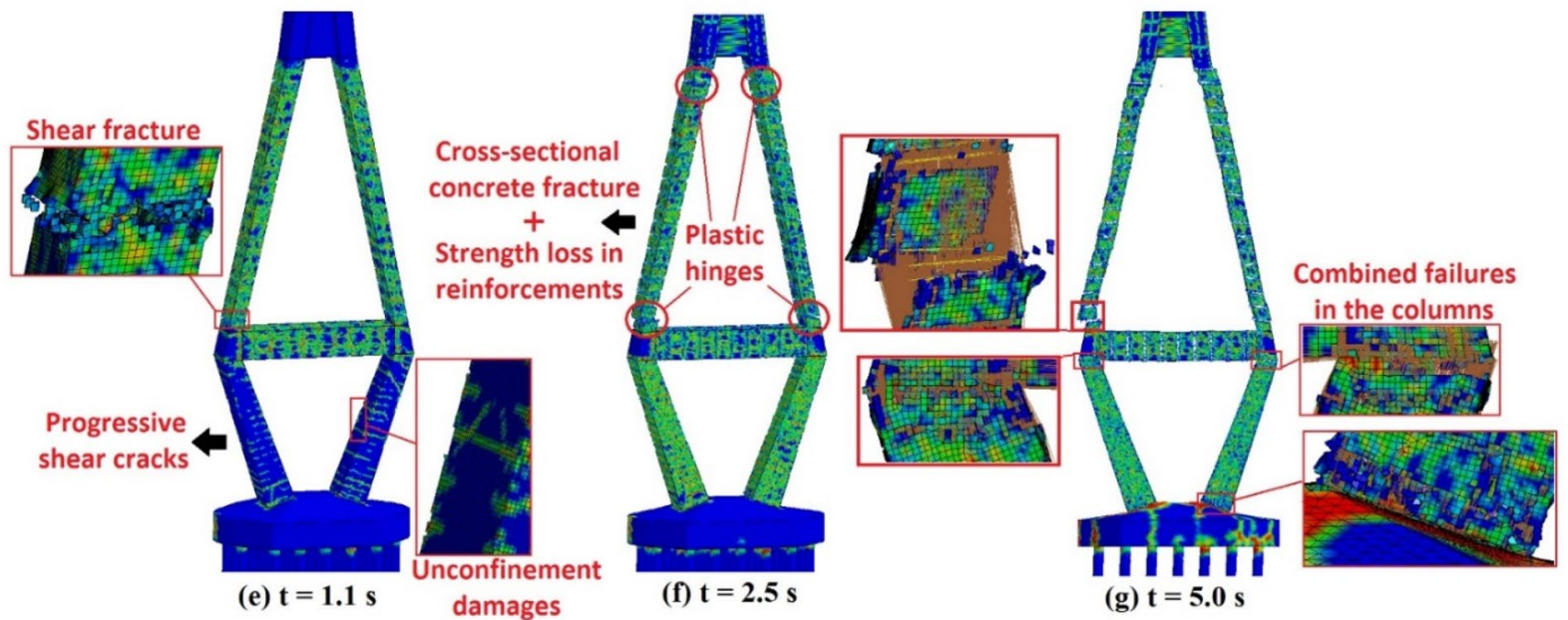

Fig. 18 Progressive damage process of the bridge pier under ship collision [120] 
in the pier columns were observed, respectively, as shown in Fig. 18.

Sha and Hao [57] experimentally studied the impact responses of scaled models of fixed-base (i.e., neglecting soil-structure interactions at the bottom boundary condition) circular bridge piers subjected to pendulum impact loading in the presence of the equivalent mass of the superstructure. Considering fixed base boundary conditions led to underestimate pier responses. In addition, influences of several parameters on the impact forces and the pier responses were evaluated through a parametric study based on the FE simulations of vessel-pier collisions. Compared to the notable sensitivity of the peak impact forces to impact velocity, impact durations were more affected by vessel mass parameter. Besides, structural parameters including pier height, superstructures mass, and the height of impact location had marginal influences on the impact force. In addition, the performance of RC bridge piers subjected to ship collision was evaluated by Yunlei et al. [60] using experimental tests on scaled models, and FE simulations of ship-pier collision considering nonlinear material models. The significant influences of the material nonlinearity on the impact results and the pier responses were concluded when for high energy collision scenarios.

\section{Columns Subjected to Impact Loads}

The vulnerability of relatively small-size RC columns commonly used in low- and medium-rise RC framed buildings subjected to lateral impact loads has been widely studied in the literature [26, 30, 52, 123-125].

Liu et al. [123] experimentally and numerically carried out a series of low-velocity impact tests on the axiallyloaded circular RC columns. An improved FE method was proposed to overcome the drawbacks of existing conventional FE modeling approaches in the prediction of impact responses of RC structures. In this method, the impact loadings were applied to RC columns which their concrete materials were modeled using a modified model providing proper confinement effects (by modifying soften behavior of the concrete), crack opening and closing (by modifying the concrete modulus), and bond-slip behaviors (by assigning discrete elements along with the longitudinal reinforcements). In addition, from a parametric study, significant influences of the reinforcement ratios on both overall and local failures, and positive effects of the axial load on the column impact resistance for small deformations were concluded. However, no sensitivity level was determined for the positive effects of axial load. With the purpose of filling this gap existing in the previous studies, Gholipour et al. [52] carried out a parametric study on the impact responses, failure modes of square $\mathrm{RC}$ columns under different lateral impact loading varying

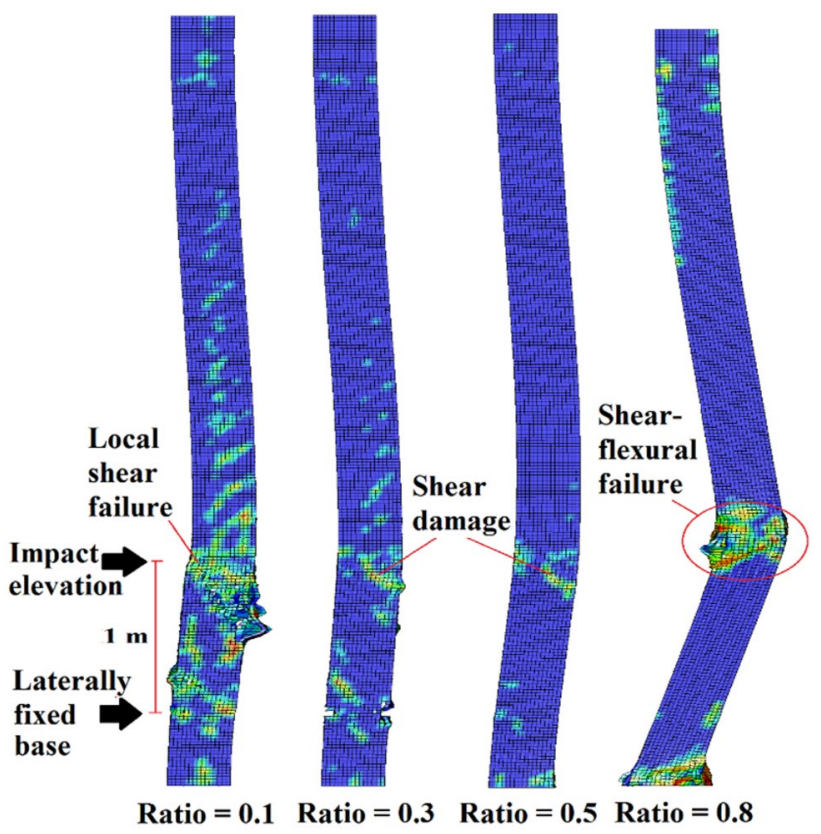

Fig. 19 Failure behaviors of RC columns with different axial loads under middle-rate impact loading [52]

in terms of axial load ratio, impact velocity, and the height of impact location. It was found that the ranges between 0.3 and 0.5 for the axial load ratio caused a substantial increase in the impact resistance of the columns as shown in Fig. 19. In addition, reducing the height of impact location led to the increase of the peak impact force and changing of the column failure mode from a global flexural mode to local shear failures. In line with these studies, the vulnerability of $\mathrm{RC}$ columns varying in terms of shear reinforcement ratio and axial load level subjected to different-energy dropweight impact tests experimentally investigated by Yilmaz et al. [125]. Reducing the values of peak and residual displacements, and the magnitude of the columns' absorbed energy was obtained with the increase of the axial load level. Besides, although both shear and flexural capacities of the columns were increased by enhancing the axial load level until a balanced level identified using the moment-axial load interaction diagrams, the ductility and energy dissipation of RC columns were reduced. Beyond this level, the axial load had a negative influence on the resistance capacity of columns.

In assessing the shear mechanisms of RC columns, Demartino et al. [26] experimentally studied the impactinduced responses of shear-deficient RC columns with different hoop spacing, and boundary conditions subjected to different-rate lateral impact loadings with velocities from $2.25 \mathrm{~m} / \mathrm{s}$ to $4.5 \mathrm{~m} / \mathrm{s}$. The governance of diagonal shear failures originated from the column base to the impact point was mostly observed as shown in Fig. 20. It was obtained that the 


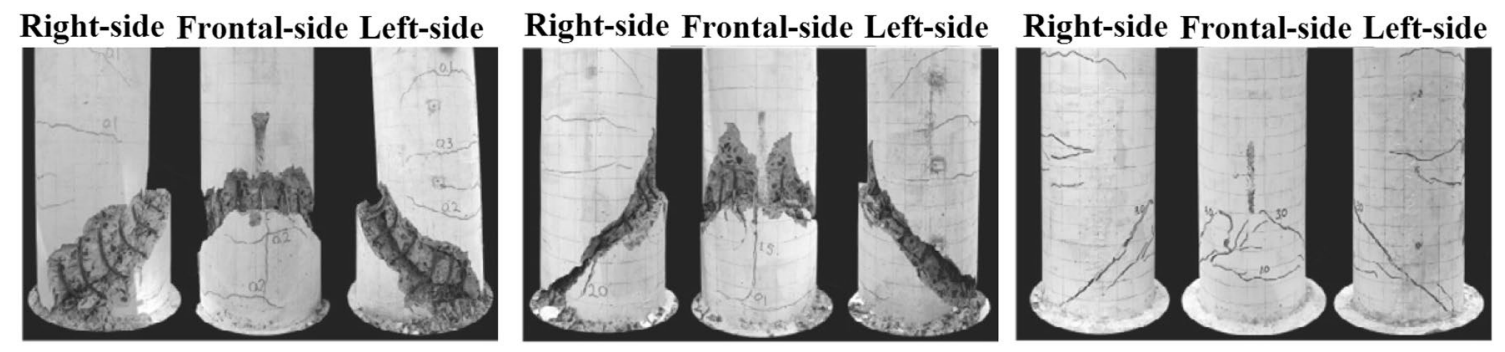

Fig. 20 The governance of shear failure on the responses of RC columns under lateral impact loads [26]

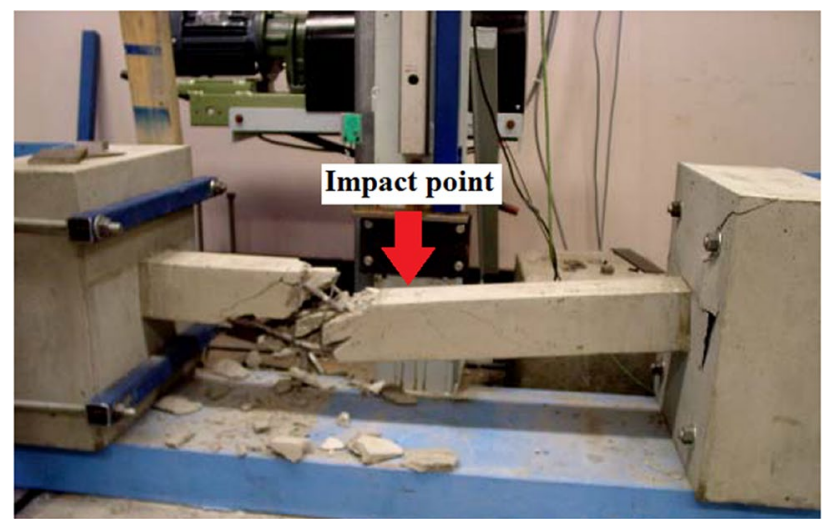

Fig. 21 Failure behavior of an RC column under mid-span impact load [124]

initial impact phase was profoundly dependent on the inertial forces and characteristics of the contact surface. In addition, more severe damages were observed in columns with a fixed base. Similarly, from a series of dropping mass impact tests of shear-deficient axially-loaded RC columns conducted by Remennikov and Kaewunruen [124], the occurrence of brittle shear failures around the impact zone was mainly observed as shown in Fig. 21 due to the mobilization of inertial forces during the initial impact phase and reducing the bending moment at the mid-span.

Unlike the studies above, the predominance of flexural failure modes on the responses of square RC columns with different cross-sectional dimensions subjected to horizontal impact loads was obtained by Cai et al. [25] when the impact loads were applied to the top positions of columns (columns' head). In addition, the influences of the columns' slenderness ratio, impact weight, and velocity parameters were evaluated on the impact responses and damage patterns of the columns. The positive influences of the impacting weight on the average value of impact forces, the impact velocity on the impact durations, and the column cross-sectional dimension on the impact forces were concluded.

Despite many studies focused on the impact responses of RC columns, the vast majority of previous works have focused on the protective design, and investigating the performance of retrofitted concrete columns using high-strength composite materials such as fiber-reinforced polymer (FRP) [126-129], carbon fiber-reinforced polymer (CFRP) [23, 130-133], and ultra-high-performance fiber-reinforced concrete (UHPFRC) [28, 56, 134, 135], or using steel jackets surrounding the core concrete such as concrete-filled steel tube (CFST) [136-146], concrete-filled double-skin steel tube (CFDST) [144-154] subjected to lateral impact loads. In some cases, the combinations of both approaches were adopted such as CFST-CFRP [133, 140, 155, 156] and CFST-FRP $[157,158]$ as a strengthening method. The positive effects of the aforementioned retrofitting techniques in the enhancement of impact resistance and mitigating the damage levels of concrete columns were mostly concluded in the previous works. However, the effectiveness of employing such approaches in enhancing the axial load carrying capacity of columns when they subjected to lateral impact loads has not been investigated in the literature. From the evaluation of the impact responses of axially-loaded CFDST columns, Aghdamy et al. [149] found initial peak impact force is most sensitive to initial impact velocity. Moreover, the duration of impact load was extremely dependent on the impact location, initial impact velocity, axial load ratio (limited to less than 0.3), and the impactor-to-column mass ratio. It was concluded that the axial load until a ratio of 0.3 had positive influences on the magnitude of impact forces, the column flexural capacity, and negative effects on both the peak and residual values of the column displacements. Table 5 presents a summary of previous works studied the influences of various parameters on the impact responses of $\mathrm{RC}$ columns.

\section{Beams and Slabs Subjected to Impact Loads}

Although applying of lateral impact loads arising from the collision of vehicles or vessels with columns is more likely than other structural members, beams or slabs utilized in framed buildings or bridges constructed in mountainous 
Table 5 Summary of studies on the influence of various parameters on the impact resistance of column members

\begin{tabular}{|c|c|c|c|}
\hline Study & Analysis & Parameter & Effectiveness \\
\hline \multirow[t]{2}{*}{ Liu et al. [123] } & \multirow[t]{2}{*}{ Experimental and Numerical } & Reinforcement ratios & Significant effects on both overall and local failures \\
\hline & & Axial load & $\begin{array}{l}\text { Positive effect on the impact resistance when the } \\
\text { column deformations are small }\end{array}$ \\
\hline \multirow[t]{3}{*}{ Gholipour et al. [52] } & \multirow[t]{3}{*}{ Numerical } & Axial load ratio & $\begin{array}{l}\text { Positive on the column resistance for the ratios } \\
\text { between } 0.3 \text { and } 0.5\end{array}$ \\
\hline & & Impact velocity & Negative effect on the length of plastic hinges \\
\hline & & Height of impact location & $\begin{array}{l}\text { Reducing the impact height changed the failure modes } \\
\text { from global flexural mode to local shear failures }\end{array}$ \\
\hline \multirow[t]{2}{*}{ Yilmaz et al. [125] } & \multirow[t]{2}{*}{ Experimental } & Shear reinforcement spacing & $\begin{array}{l}\text { Increased the maximum and the residual displacement } \\
\text { values, the energy absorption capacities, and shear } \\
\text { cracks }\end{array}$ \\
\hline & & Axial load level & $\begin{array}{l}\text { Positive on the columns impact resistance for the } \\
\text { levels less than a specific balanced level }\end{array}$ \\
\hline \multirow[t]{4}{*}{ Demartino et al. [26] } & \multirow[t]{4}{*}{ Experimental } & Hoop spacing & Significant effects on the column shear capacity \\
\hline & & Boundary conditions & More severe damage for fixed base columns \\
\hline & & Contact surface & Significant effects on the initial impact phase \\
\hline & & Column Inertia & \\
\hline \multirow[t]{4}{*}{ Cai et al. [25] } & \multirow[t]{4}{*}{ Experimental } & Height of impact location & $\begin{array}{l}\text { Changing the column failure mode from shear to } \\
\text { flexural failures with increasing the height of impact } \\
\text { load }\end{array}$ \\
\hline & & Column cross-sectional dimension & Positive on the magnitude of impact forces \\
\hline & & Impact weight & Positive on the average values of impact forces \\
\hline & & Impact velocity & Positive on the impact durations \\
\hline \multirow[t]{4}{*}{ Aghdamy et al. [149] } & \multirow[t]{4}{*}{ Experimental and Numerical } & Impact location & Significant effects on the impact duration \\
\hline & & Impact velocity & \\
\hline & & Impactor-to-column mass ratio & \\
\hline & & Axial load ratio & $\begin{array}{l}\text { Significant positive on the impact forces, the column } \\
\text { flexural capacity until a ratio of } 0.3\end{array}$ \\
\hline Alam et al. [140] & Numerical & Axial load & Positive on the column impact resistance \\
\hline Alam et al. [156] & Numerical & Axial load & Positive until $45 \%$ of the column capacity \\
\hline Chen et al. [157] & Experimental & Axial load & Positive on the column impact resistance \\
\hline
\end{tabular}

areas may also be subjected to impact loads arising from the falling objects and rocks. Hence, many researchers have attempted in the literature investigating the impact forces, structural responses, and failure behaviors of RC beams analytically [2, 159-164], numerically [1, 165-176], and experimentally [18, 20, 166, 177-187] under low-rate [1, 2, 171, $175,185,187]$ and relatively high rate [188-191] impact loads by focusing on the influence of the structural-related parameters such as the beam inertia $[170,175,176,188$, 189], longitudinal [2] and transverse [18, 186, 192] reinforcements, and loading related parameters such as impact weight and velocity [185, 186]. A summary of previous studies investigating the effectiveness of various parameters on the impact responses of RC beams is presented in Table 6.

Fujikake et al. [2] experimentally and analytically studied the impact force and maximum mid-span deflection of $\mathrm{RC}$ beams varying in the ratio of longitudinal reinforcements under different drop-weight impact loadings with low to medium ranges of the impact energy and velocity.
With the purpose of evaluating the flexural failure modes of RC beams, they sufficiently reinforced with transverse reinforcements against shear failure modes. It was found that well-reinforced RC beams against shear failures can undergo overall response mode under low-rate impact loads, and localized response mode along with compressive damages in the concrete cover with increasing of the impact velocity. In addition, a simplified two-degree-of-freedom model was proposed to calculate both localized and overall response phases based on load-displacement responses of RC beams under impact loads as shown in Fig. 22.

Pham and Hao [1] numerically and analytically studied the effect of global stiffness of structure on the impact behavior of RC) beams. For impact velocities more than $1 \mathrm{~m} / \mathrm{s}$, it was concluded that the initial impulse and peak impact force were not sensitive to the structure of global stiffness. While the global stiffness governed the following impact impulses during the free-vibration phase of the beam response. Delayed activation of the flexural stiffness in the 
Table 6 Summary of studies on the various parameters on the impact resistance of beam members obtained by various studies

\begin{tabular}{|c|c|c|}
\hline Study & Analysis & Parameter \\
\hline Pham and Hao [1] & Numerical and analytical & $\begin{array}{l}\text { Beam's global stiffness by the beam } \\
\text { span and reinforcements } \\
\text { Beam's local stiffness }\end{array}$ \\
\hline Fujikake et al. [2] & Experimental and analytical & $\begin{array}{l}\text { Drop height } \\
\text { Amount of longitudinal reinforcemer }\end{array}$ \\
\hline Gholipour et al. [168] & Numerical & Impact velocity \\
\hline Jin et al. [169] & Experimental & $\begin{array}{l}\text { Impactor's mass } \\
\text { Beam span length }\end{array}$ \\
\hline Guo et al. [170] & Numerical and analytical & $\begin{array}{l}\text { Relative mass of impactor to beam } \\
\text { Impact velocity }\end{array}$ \\
\hline Li et al. [172] & Numerical & $\begin{array}{l}\text { Impactor's mass } \\
\text { Impact velocity } \\
\text { Inclination angle of impactor } \\
\text { Concrete strength }\end{array}$ \\
\hline Li et al. [174] & Numerical & Impactor geometry \\
\hline
\end{tabular}

Effectiveness

Significant on the impact responses and failure modes at later stages than initial impulse

Significant on the beam responses in the first impact impulse

The beam failures tended to local failures with increasing the drop weight

Lower amount caused overall flexural failures, and higher amounts caused both local and overall failures

The beams tended to local failures with increasing impact loading rate

Significant effects on the local damage of concrete; marginal effects on the impact force and the beam deflections

Significant positive on the impact duration

Significant negative on the peak impact force; Significant positive on the impact duration

Significant positive on the peak impact force until a ratio of 1.0

Significant positive on the peak impact force

Significant positive the impact force and the beam displacement

Significant effects on the impact force; Marginal effects on the beam displacements

Flat-head impactor generates the highest peak impact force and shortest duration, and had marginal effects on the beam displacements; Curve-head impactor caused more sever damages

The curvature radius of impactor's head Significant positive on the peak impact force; Negative on the impact duration

Inclination angle of impactor

Significant effects on the peak impact force generated by flat-head impactors

Plastic hinge

Boundary conditions

Concrete strength

Marginal on the impact force and duration; Significant on the beam residual displacement and the damage levels

Significant effects on the beam failure modes; Marginal effects on the impact force and the beam displacement

Significant effects on the beam impact behavior and demand

Plastic hinge position

Span/depth ratio

Impact velocity

Yan et al. [183] Experimental and Numerical Impact velocity

Adhikary et al. [185] Experimental and Numerical Beam-to-impactor mass ratio

Longitudinal reinforcement ratio

Concrete strength

Boundary conditions
Significant on the force wave propagation in the beam

Changing the beam failure mode from flexural to shear mode with increasing impact velocity

Large mass impacting with low velocity caused smaller peak impact forces and larger peak deflections

Positive on the peak impact force and negative on the beam peak deflections

Fixed-end beams endured more peak impact forces than pinned-end beams 
Table 6 (continued)

\begin{tabular}{|c|c|c|c|}
\hline Study & Analysis & Parameter & Effectiveness \\
\hline \multirow[t]{3}{*}{ Zhao et al. [186] } & \multirow[t]{3}{*}{ Experimental and Numerical } & Beam span & $\begin{array}{l}\text { Positive on the predomination of stress wave } \\
\text { propagation on the impact response }\end{array}$ \\
\hline & & Transverse reinforcement ratio & Positive on the shear resistance of beams \\
\hline & & Impact velocity & $\begin{array}{l}\text { Positive on the occurrence of local shear } \\
\text { failures }\end{array}$ \\
\hline Cotsovos et al. [188] & Experimental and Numerical & loading rate & $\begin{array}{l}\text { Extremely related to the beam inertial forces; } \\
\text { Negative effects on the length of plastic } \\
\text { hinges }\end{array}$ \\
\hline Ozbolt and Sharma [192] & Numerical & $\begin{array}{l}\text { Amount of shear reinforcement } \\
\text { Loading rate }\end{array}$ & $\begin{array}{l}\text { Significantly affects the crack pattern } \\
\text { Significant effects on the failure modes }\end{array}$ \\
\hline Pham et al. [193] & Experimental and Numerical & Contact stiffness & $\begin{array}{l}\text { Significant effects on the peak impact, the } \\
\text { beam demands force, and the impact } \\
\text { duration; Marginal effects on the impact } \\
\text { impulse, energy, and the beam displace- } \\
\text { ments }\end{array}$ \\
\hline
\end{tabular}

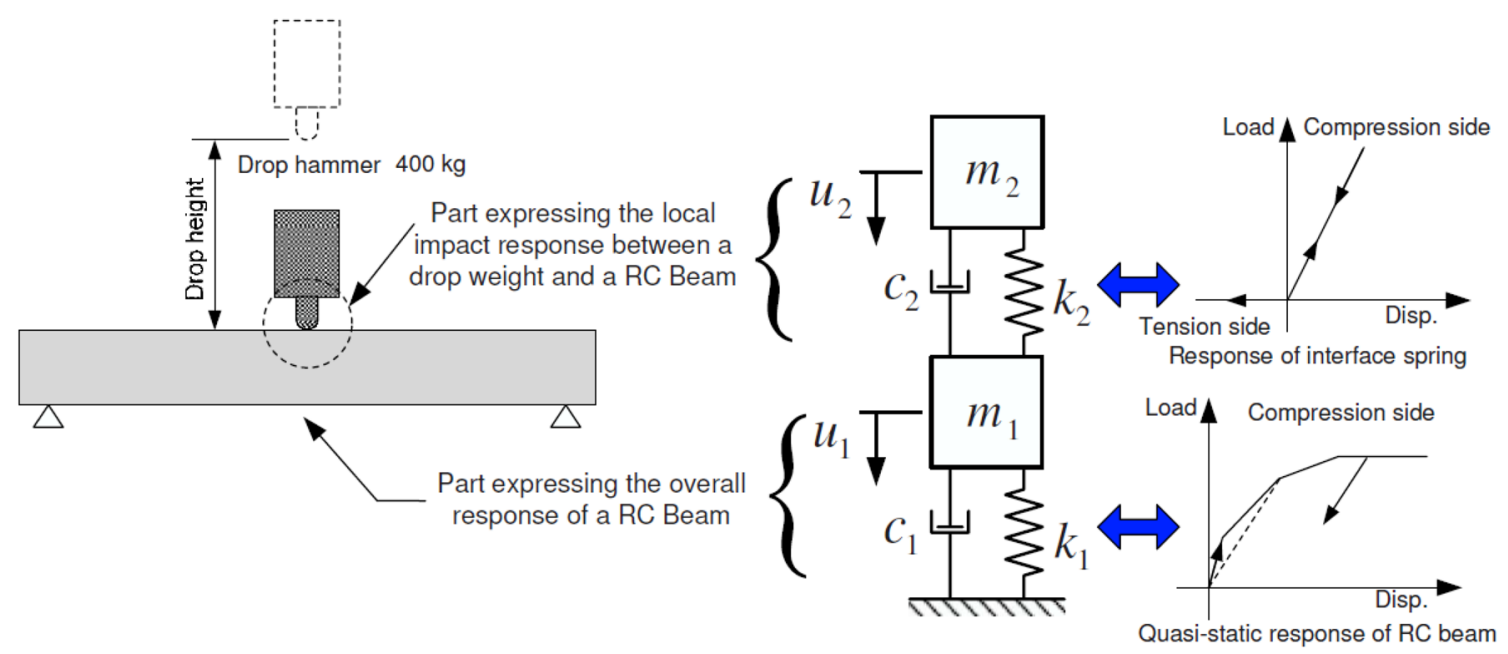

Fig. 22 Simplified two-degree-of-freedom model of the responses of RC beams under impact loads proposed by Fujikake et al. [2]

following impact phases was declared as the main cause of such a conclusion. In addition, it was revealed that the secondary peaks of impact forces are profoundly related to the stress wave propagation in the impactor and the impacted beam. Also, the negligible effects of several structural parameters such as the ratio of longitudinal rebars, the beam span length on the initial impact impulse were concluded. Besides, Pham and Hao [193] found that the impact force and the responses of RC beams are very sensitive to the contact stiffness and conditions between the impactor and the beam. Thereafter, the significant influences of the impactor geometry and interlayer between the impactor and the beam were concluded from a numerical study of RC beams done by [174] under drop-weight impact loads. Accordingly, the curvature radius of the impact had positive on the peak impact force, and the negative effect on the duration of impact force. Also, more severe damages were observed in the beam under hemispherical and curved impactors rather than those exposed to a flat-head impactor.

The influences of several structural-related parameters including the beam span length, cross-section area, shear span effective depth ratios, longitudinal and transverse ratios, and shear to bending resistance ratios on the impact responses RC beams under low-rate impact loadings were evaluated by Adhikary et al. [185]. It was found that although the increase of longitudinal reinforcement ratio enhanced the flexural resistance of the beams through reducing the beam deflections, the predominance of shear failures was obtained by observing diagonal cracks and shear plug damages. 
In spite of the reviewed studies above investigating the behaviors of RC beams under low- and medium-rate impact loads, there exist many research works addressing the impact responses of RC beams under high-rate impact loads. Zhan et al. [191] experimentally investigated the failure behaviors of RC beams under high-rate impact loadings with impact velocities between $6 \mathrm{~m} / \mathrm{s}$ and $13 \mathrm{~m} / \mathrm{s}$. Based on the results from a parametric study, two empirical formulas quantitatively describing the relationships between the impact loading energy and the impact responses of beams such as deflection, and flexural load-carrying capacity were developed.

Understanding the mechanism of stress wave propagation in RC structures plays the most key role in the determination of their shear capacity [188], demands [176], and failure behaviors $[194,195]$. The effects of stress wave propagation in evaluating the impact responses of RC beams were considered by Cotsovos [188] to calculate the shear resistance, by Pham and Hao [176] to estimate the shear force diagram, and by Zhao et al. [194] to assess the shear failure and damages. Cotsovos et al. [188] concluded that the responses and resistance capacity of RC structures under high-rate impact loading are profoundly affected by the inertia forces and stress wave propagation at initial response phase of the structure activated in a partial length of RC beam called "effective length" $\left(L_{\text {eff }}\right)$ which led to different bending moment diagrams compared to those achieved under low-rate impact loadings as shown in Fig. 23. Afterwards, the load-carrying capacity of RC beams under high-rate impact loads was investigated by Cotsovos [189] using a proposed simplified method based on the concept of stress wave propagation and its travel time in RC structures. According to this method, stress waves generated under high-rate impact loads do not necessarily reach the beam supports during the initial phase of the response. Under such loading conditions, the appearance of negative moments on the upper surface of the beam with a distance of $L_{\text {eff }}$ as shown in Fig. 23 is very likely. It was concluded that the length of $L_{\text {eff }}$ decreased with increasing the velocity of impact loading.

In line with the works carried out by Cotsovos et al. [188, 189], Pham and Hao [176] investigated the position of plastic hinges formed in RC beams, and the dynamic demand diagrams for the shear force and bending moment under impact loads by assuming the linear distribution of inertia force along the beam. By assuming the mobilization of inertial forces in a partial length of the beam (i.e., effective length), the formation of plastic hinges was expected inside the effective length between the stationary points where the beam's accelerations and inertia were zero as shown in Fig. 24. Besides, the influences of the plastic hinge and boundary conditions on the behavior of RC beams under low-rate impact loads were assessed by Pham and Hao [175]. Considering the location of plastic hinges in the determination of the equivalent stiffness of RC beams was extremely recommended. Also, it was obtained that the boundary conditions had marginal effects on the peak value and the duration of the impact force.

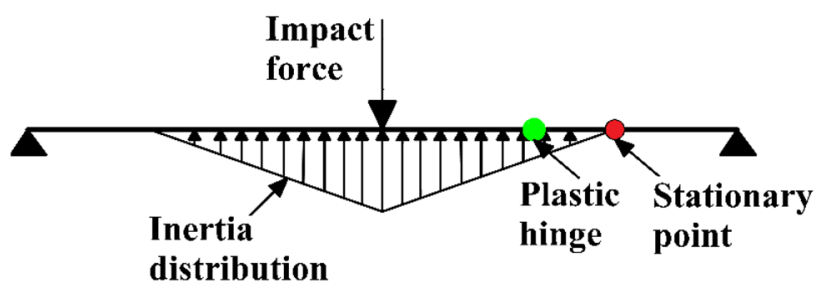

Fig. 24 Estimation of plastic hinge location in RC beams under impact load by Pham and Hao [52]

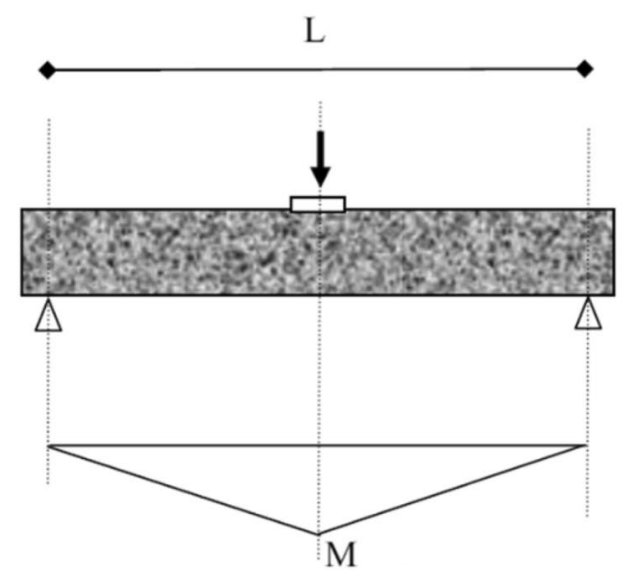

(a) Low-rate impact load

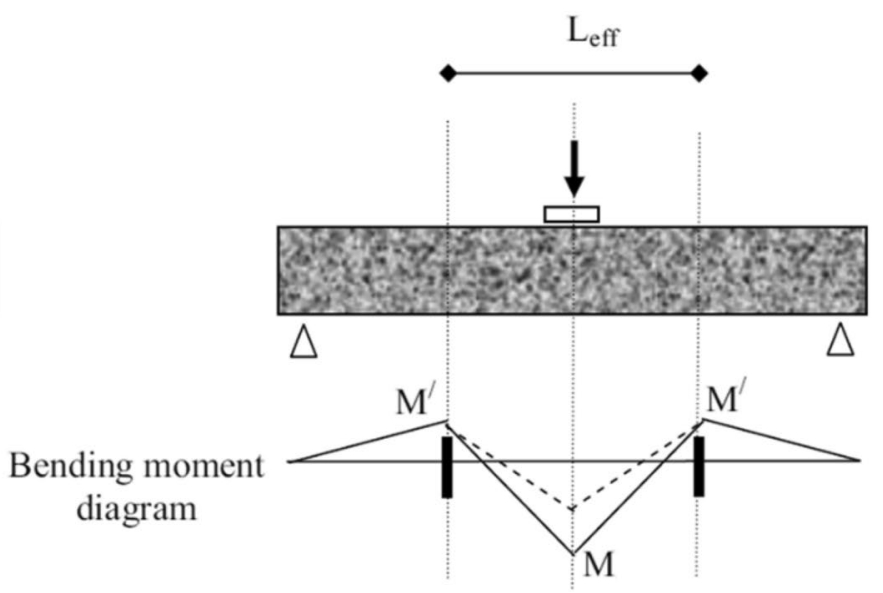

(b) High-rate impact load

Fig. 23 Schematic of bending moment diagrams of the RC beam under a high-rate, $\mathbf{b}$ low-rate impact loads [188] 
Since beams are basically designed to fail in flexural modes, recognizing their shear mechanisms is the topic of importance which has been investigated by several previous studies experimentally [20, 181, 186], numerically [192, 194], and analytically $[195,196]$. The shear failure mechanism of RC beams under drop-weight impact loading was experimentally and numerically studied by Zhao et al. [186] by varying various parameters including beam span, transverse reinforcement ratio, impact mass, and impact velocity. It was mainly concluded that the beams tended to fail in shear modes through the occurrence of localized shear plug and diagonal cracks around the impact zone shortly after the onset of impact loading with increasing the impact velocity. Based on the experimental observations, shear failure modes were categorized into three types as shown in Fig. 25 including: (1) diagonal cracks and shear plug failure around the impact zone under high-rate impact loading (Type I), (2) inclined flexural-shear cracks and damages propagated from the supports to the impact point under low-rate impact loading (Type II), (3) a combined failure mode (Type I+ II).

The inability of existing simplified single-degree-of-freedom methods in assessing the shear failures of beams under impact loads motivated Yi et al. [195] to propose a simplified approach predicting the shear resistance and evaluating the occurrence probability of shear failures in an effective length of RC beams under impact loads considering the effects of stress wave propagation. Since the proposed method was only based on shear capacity and demand of beams without considering shear deformation, quantifying the shear damage was not possible. Hence, Zhao et al. [194] improved their previous approach proposed in [186] to a simplified three-degree-of-freedom as shown in Fig. 26 by considering the beam deformations in both shear and flexural response modes. The positive influences of the beam span length on the duration of the impact forces were obtained compared to its negative effects on the mean of impact forces.

From an experimental investigation by Saatci and Vecchio [18] on the shear behaviors of RC beams varying in the ratio of shear reinforcements under high-rate impact loading with an impact velocity of $8 \mathrm{~m} / \mathrm{s}$, it was observed that all specimens with different shear resistances suffered severe shear cracks and shear plug failures. Moreover, by measuring the velocity of impact force wave propagating from the impact point to supports, it was revealed that the velocity of force wave could be significantly smaller than that of longitudinal and shear wave velocity with totally different inherent. From another experimental study done by Kishi et al. [20], failure behaviors of twenty-seven simplysupported RC beams without shear rebar were investigated under drop-weight impact loading. The occurrence probability of flexural failure modes in the beams without shear rebar was concluded under low-rate impact loads. However, the beams tended to fail in shear modes by increasing the impact velocity. Figure 27 shows the typical failure modes including global and localized shear and flexural failures in $\mathrm{RC}$ beams with simple supports varying in shear and flexural strengths under different-rate impact loads based on the information and observations from the previous works [2, $20,181,185,188]$. It is observed that RC beams with lowshear and low-flexural strengths under low- and middle-rate impact loads [20, 181, 185] suffer overall shear and flexural failures. Moreover, beams with sufficient flexural-shear
Fig. 25 Typical shear failure modes in RC beams under different-rate impact loadings [186]

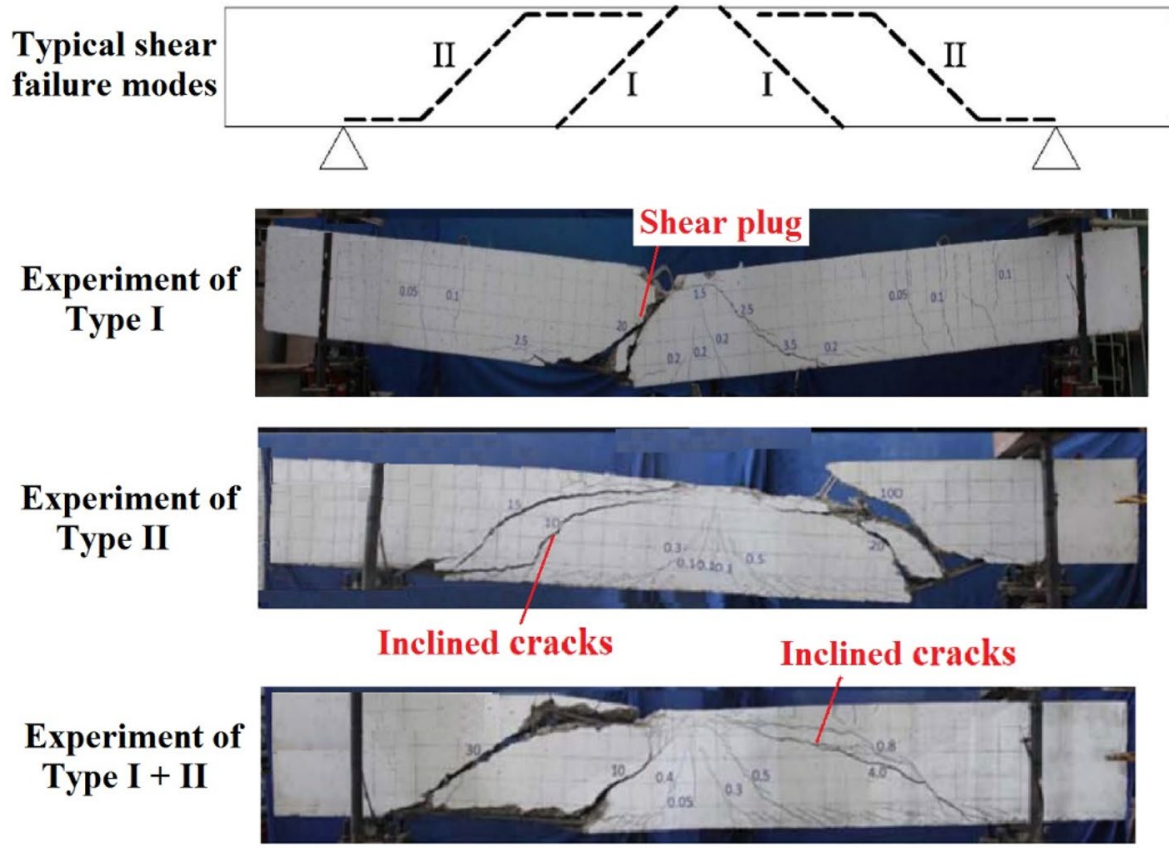




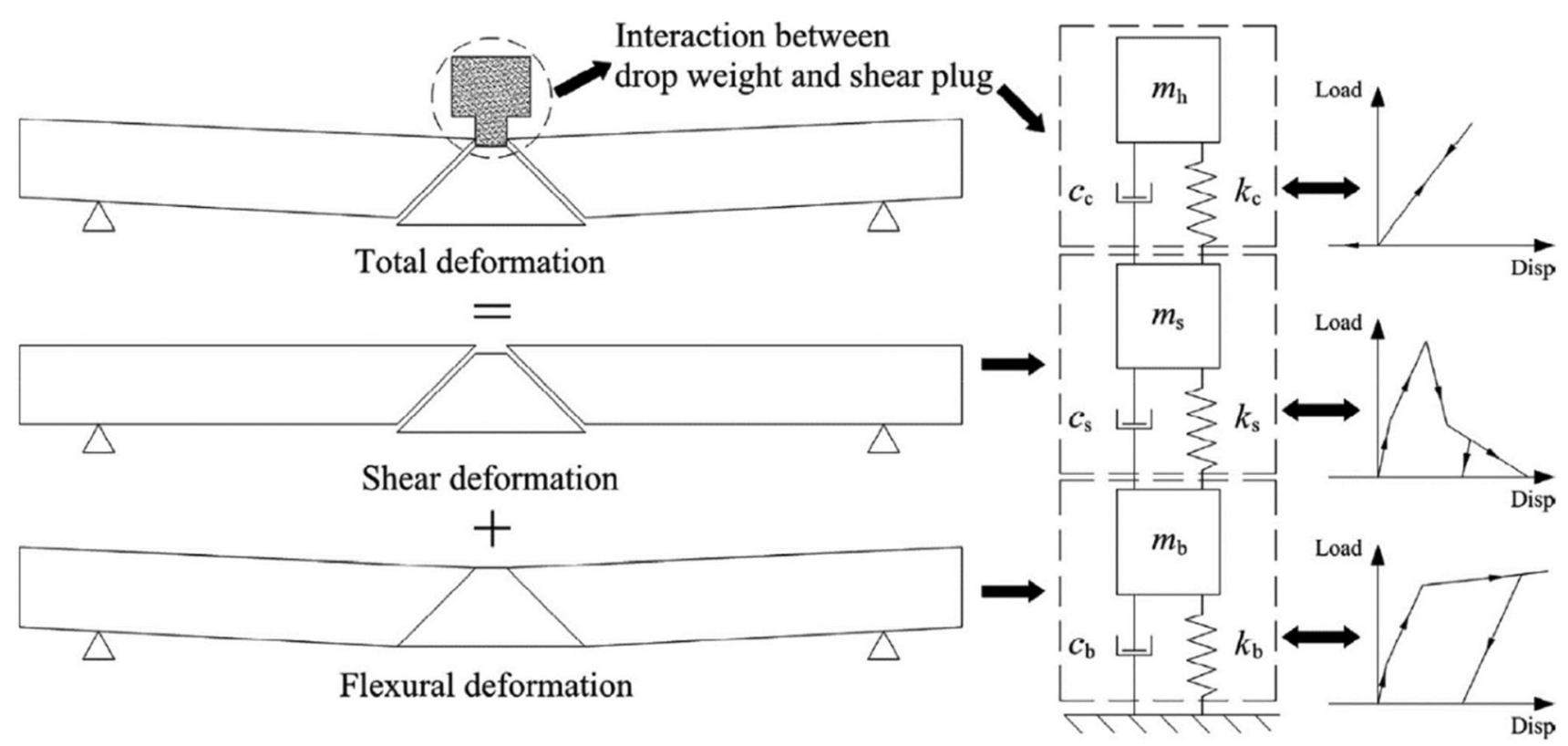

Fig. 26 The simplified three-degree-of-freedom model proposed by Zhao et al. [194]

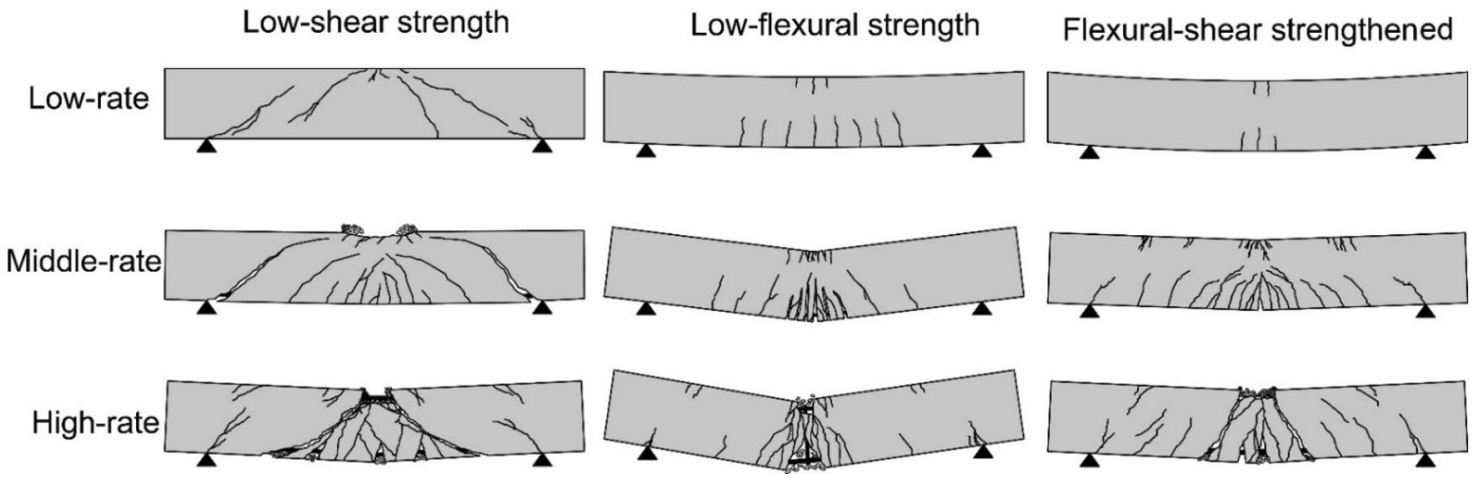

Fig. 27 Typical failure modes of RC beams varying in shear and flexural strengths under different-rate impact loads [165]

strength endure minor flexural cracks under low-rate impact and global flexural-shear damages under middle-rate impacts [2]. When RC beams are subjected to high-rate impact loads, compared to the formation of a plastic hinge in the beam with low flexural strength, the occurrence of localized shear plugs around the impact zone is observed in the beams with sufficient flexural strengths [20, 181].

With the purpose of protective design of RC structures against impact loads, several research works can be found in the literature investigating the performance of $\mathrm{RC}$ beams retrofitted and reinforced by high-strength composite materials such FRP [197, 198], steel fiber reinforced concrete (SFRC) [199] CFRP laminates [200-202], UHPFRC [187], recycled aggregate concrete (RAC) [184], glass FRP (GFRP) rebars [203], engineered cementitious composites (ECC) containing polyvinyl alcohol (PVA) fibers [204], high strength steel wire mesh and high performance mortar (HSSWM-HPM) [182], coconut fibre reinforced concrete (CFRC) beams strengthened with flax fibre reinforced polymer (FFRP) [205], or strengthened by steel jackets [138, 205]. Also, there exist some limited numbers of research works studying the performance of precast concrete beams under impact loads [172, 183].

Slabs are also one of the most common structural members which are commonly used in connection with supporting beams. Many studies existing in the literature evaluating the dynamic responses, and failure behaviors of concrete slabs and plates under low- [206-212], moderate- [213] and high-rate [214] impact loads analytically [214-216], numerically [213, 215, 217-219], experimentally [22, 208, 211, 218, 220, 221]. Generally, concrete slabs underwent two typical failure modes including globally distributed crack 


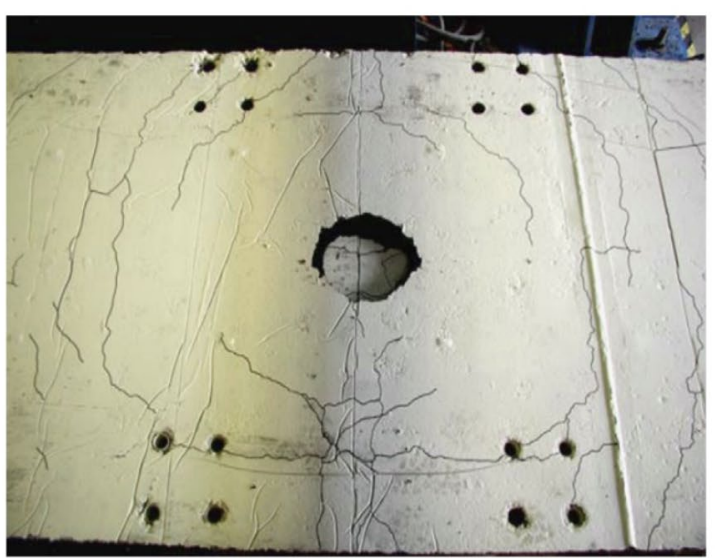

(a) Punching shear failure [22]

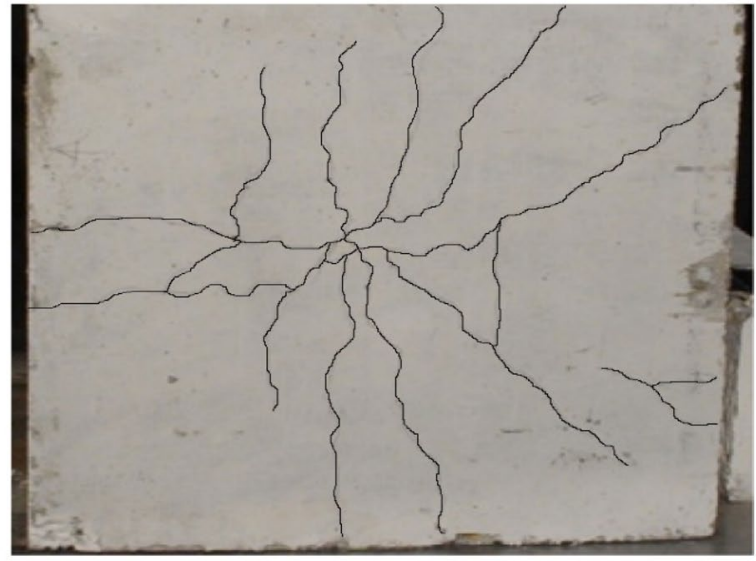

(b) Distributed cracks [208]

Fig. 28 Typical failure modes of concrete slabs under different impact loads

patterns $[209,211]$ under low-rate impact loads, and localized failure and punching shear failure [22] under high-rate and projectile [222-229] impact loads and shown Fig. 28a, b. Like as those retrofitting approaches used to protect of concrete columns and beams against impact loads, several research works focused on investigating the performance of concrete slabs strengthened with composite materials such as steel fibers [206], FRP [212], CFRP [230], ultra-high performance concrete (UHPC) [207], UHPFRC [208] slurryinfiltrated fibrous concrete (SIFCON) [212], hybrid bamboo fiber (HBF) [231], coconut fibre [212, 232] and reinforced by FRP-bars [233].

The main objectives of utilizing these protective design techniques are to mitigate the brittle damages and enhancing both shear and flexural resistance of concrete structures in harsh environments or under extreme loadings. Therefore, special recommendations should be considered in utilizing these methods with regard to the applications of the structures. For instance, the use of excessive high-strength materials in the tensile surface of RC beams may lead to the occurrence of early shear failures in beams prior to flexural modes.

\section{Conclusion}

This paper presents a state-of-the-art review of responses and behaviors of different concrete structures subjected to lateral impact loads. First, the basic theories of impact loadings and the response mechanisms of concrete structures to such extreme loads were introduced. Then, the specifications existing in the current design codes and guidelines regarding impact loads and their limitations were discussed. In addition, the dynamic responses and failure behaviors of concrete structures including bridge piers subjected to vehicle and vessel collisions, or isolated structural members such as concrete columns (commonly used in low- and mediumrise buildings), beams, and slabs under lateral impact loads of rigid objects analyzed using simplified analytical, finite element simulations, and experimental methods were comprehensively reviewed. Moreover, the influences of various load- and structural-related parameters on the impact responses of concrete structures were studied.

It was revealed that the impact loads predicted by the current guidelines may be unconservative due to omitting the amplification dynamic effects such as inertia and strain rate effects. Also, despite many attempts in recognizing the failure modes and especially shear failures of RC bridge piers under vehicle collisions, there is no recommendation in the current design codes considering the damage states of the impacted structure in the prediction of equivalent impact loads.

From the review on the influences of various parameters on the impact responses of RC columns and piers under lateral impact loads arising from vessel or vehicle collisions, it was obtained that the effectiveness of the axial load parameter has not been rigorously explored. However, most of the previous researches have studied the impact capacities of axially-loaded structures when they were exposed to their service levels of axial loads.

By reviewing vessel-pier collision studies, the vast majority of these research works concluded the significant influences of the dynamic parameters of both striking vessels and struck structures such as the pier inertia, axial load ratio (superstructure inertia-related), geometry, and soil-structure interaction behavior on the impact responses of bridge piers. Hence, the inability of the current design codes in estimating accurate and reasonable impact loads and responses under 
vessel collisions was found due to neglecting the effects of these parameters.

Acknowledgements The research is financially supported by the Ministry of Science and Technology of China (Grant No. 2017YFC0703603), the National Natural Science Foundation of China (Grant No. 51678322), the Taishan Scholar Priority Discipline Talent Group program funded by the Shandong Province, and the first-class discipline project funded by the Education Department of Shandong Province.

\section{Compliance with ethical standards}

Conflict of interest The authors declare that there is no conflict of interests regarding the publication of this paper.

Open Access This article is licensed under a Creative Commons Attribution 4.0 International License, which permits use, sharing, adaptation, distribution and reproduction in any medium or format, as long as you give appropriate credit to the original author(s) and the source, provide a link to the Creative Commons licence, and indicate if changes were made. The images or other third party material in this article are included in the article's Creative Commons licence, unless indicated otherwise in a credit line to the material. If material is not included in the article's Creative Commons licence and your intended use is not permitted by statutory regulation or exceeds the permitted use, you will need to obtain permission directly from the copyright holder. To view a copy of this licence, visit http://creativecommons.org/licenses/by/4.0/.

\section{References}

1. Pham TM, Hao H (2018) Influence of global stiffness and equivalent model on prediction of impact response of RC beams. Int $\mathrm{J}$ Impact Eng 113:88-97

2. Fujikake K, Li B, Soeun S (2009) Impact response of reinforced concrete beam and its analytical evaluation. J Struct Eng 135(8):938-950

3. CEN (2003) Eurocode 1: actions on structures. European Committee for Standardization, Brussels

4. Saatci S (2007) Behaviour and modelling of reinforced concrete structures subjected to impact loads. Ph.D. dissertation, University of Toronto, Canada

5. Li QM, Reida SR (2005) Local impact effects of hard missiles on concrete targets. Int J Impact Eng 32:224-284

6. Bangash MYH (1993) Impact and explosion: structural analysis and design. CRC Press, Boca Raton

7. AASHTO (2009) Guide specifications and commentary for vessel collision design of highway bridges, 2nd edn. American Association of State Highway and Transportation Officials, Washington

8. CEN (2002) Actions on structures. Part 1-7: general actionsaccidental actions. European Committee for Standardization. BS EN 1991-1-1, Brussels, Belgium

9. CMR (2005) General code for design of railway bridges and culverts, TB10002.1-2005, China Ministry of Railways, China Railway Press, Beijing, China (in Chinese)

10. AASHTO-LRFD (2012) LRFD bridge design specifications. American Association of State Highway and Transportation Officials, Washington, DC, USA
11. Abdelkarim OI, ElGawady MA (2016) Performance of hollowcore FRP-concrete-steel bridge columns subjected to vehicle collision. Eng Struct 123:517-531

12. Abdelkarim OI, ElGawady MA (2017) Performance of bridge piers under vehicle collision. Eng Struct 140:337-352

13. JSCE (2004) Subcommittee of impact problems of JSCE: practical methods for impact test and analysis. In: Kishi N (ed) Japan Society of Civil Engineers, Japan

14. AS 1170.1 (1989) AS/NZS 1170.1:1988: structural design actions-permanent, imposed and other actions, Australia

15. UK's Highways Agency (2004) The design of highway bridges for vehicle collision loads. BD 60/04. Department for Transport, UK

16. LS-DYNA 971 (2017) Livermore Software Technology Corporation, Livermore, CA, USA

17. ABAQUS (2010) Analysis user's manual version 6.10, volume I to VI, ABAQUS, Inc. an Dassault Systémes, Providence, RI, USA

18. Saatci S, Vecchio FJ (2009) Effects of shear mechanisms on impact behavior of reinforced concrete beams. ACI Struct J 106(1):78-86

19. Bhatti AQ, Kishi N, Mikami H, Ando T (2009) Elasto-plastic impact response analysis of shearfailure- type RC beams with shear rebars. Mater Des 30(3):502-510

20. Kishi N, Mikami H, Matsuoka KG, Ando T (2002) Impact behavior of shear-failure-type RC beams without shear rebar. Int J Impact Eng 27(9):955-968

21. Xiao Y, Li B, Fujikake K (2017) Behavior of reinforced concrete slabs under low velocity impact. ACI Struct J 114(3):643-658

22. Zineddin M, Krauthammer T (2007) Dynamic response and behavior of reinforced concrete slabs under impact loading. Int J Impact Eng 34(9):1517-1534

23. Sha YY, Hao H (2015) Laboratory tests and numerical simulations of CFRP strengthened RC pier subjected to barge impact load. Int J Struct Stab Dyn 15(02):1450037

24. Do TV, Pham TM, Hao H (2018) Dynamic responses and failure modes of bridge columns under vehicle collision. Eng Struct 156:243-259

25. Cai J, Ye JB, Chen QJ, Liu X, Wang YQ (2018) Dynamic behaviour of axially-loaded RC columns under horizontal impact loading. Eng Struct 168:684-697

26. Demartino C, Wu JG, Xiao Y (2017) Response of shear-deficient reinforced circular RC columns under lateral impact loading. Int J Impact Eng 109:196-213

27. El-Tawil S, Severino E, Fonseca P (2005) Vehicle collision with bridge piers. J Bridge Eng 10(3):345-353

28. Fan W, Xu X, Zhang Z, Shao X (2018) Performance and sensitivity analysis of UHPFRC-strengthened bridge columns subjected to vehicle collisions. Eng Struct 173:251-268

29. Sharma H, Gardoni P, Hurlebaus S (2014) Probabilistic demand model and performance-based fragility estimates for RC column subject to vehicle collision. Eng Struct 74:86-95

30. Thilakarathna HMI, Thambiratnam DP, Dhanasekar M, Perera N (2010) Numerical simulation of axially loaded concrete columns under transverse impact and vulnerability assessment. Int J Impact Eng 37:1100-1112

31. Cao R, El-Tawil S, Agrawal AK, Xu X, Wong W (2019) Heavy truck collision with bridge piers: computational simulation study. J Bridge Eng 24(6):04019052

32. Cao R, El-Tawil S, Agrawal AK, Xu X, Wong W (2019) Behavior and design of bridge piers subjected to heavy truck collision. J Bridge Eng 24(7):04019057

33. Cao R, El-Tawil S, Agrawal AK, Xu X, Wong W (2019) Performance-based design framework for bridge piers subjected to truck collision. J Bridge Eng 24(7):04019064 
34. Abdelkarim OI, ElGawady MA (2016) Design of short reinforced concrete bridge columns under vehicle collision. Transp Res Rec 2592(1):27-37

35. Agrawal AK, Liu GY, Alampalli S (2013) Effects of truck impacts on bridge piers. Adv Mater Res 639:13-25

36. AuYeung S, Alipour A (2016) Evaluation of AASHTO suggested design values for reinforced concrete bridge piers under vehicle collisions. Transp Res Rec 2592(1):1-8

37. Chen L, El-Tawil S, Xiao Y (2016) Reduced models for simulating collisions between trucks and bridge piers. J Bridge Eng 21(6):04016020

38. Chen L, El-Tawil S, Xiao Y (2017) Response spectrum-based method for calculating the reaction force of piers subjected to truck collisions. Eng Struct 150:852-863

39. Chen L, Xiao Y, El-Tawil S (2016) Impact tests of model $\mathrm{RC}$ columns by an equivalent truck frame. J Struct Eng 142(5):04016002

40. Tsang HH, Lam NT (2008) Collapse of reinforced concrete column by vehicle impact. Comput Aided Civ Inf 23(6):427-436

41. Zhou D, Li R, Wang J, Guo C (2017) Study on impact behavior and impact force of bridge pier subjected to vehicle collision. Shock Vib 2017

42. Zhou D, Li R (2018) Damage assessment of bridge piers subjected to vehicle collision. Adv Struct Eng 21(15):2270-2281

43. Auyeung S, Alipour A, Saini D (2019) Performance-based design of bridge piers under vehicle collision. Eng Struct 191:752-765

44. Cai C, He Q, Zhu S, Zhai W, Wang M (2019) Dynamic interaction of suspension-type monorail vehicle and bridge: numerical simulation and experiment. Mech Syst Signal Process 118:388-407

45. Chen L, Wu H, Fang Q, Zhang T (2018) Numerical analysis of collision between a tractor-trailer and bridge pier. Int J Protect Struct 9(4):484-503

46. Chung CH, Lee J, Gil JH (2014) Structural performance evaluation of a precast prefabricated bridge column under vehicle impact loading. Struct Infrastruct E 10(6):777-791

47. Yi NH, Choi JH, Kim SJ, Kim JHJ (2015) Collision capacity evaluation of RC columns by impact simulation and probabilistic evaluation. J Adv Concr Technol 13(2):67-81

48. Sharma H, Hurlebaus S, Gardoni P (2012) Performance-based response evaluation of reinforced concrete columns subject to vehicle impact. Int J Impact Eng 43:52-62

49. Sharma H, Gardoni P, Hurlebaus S (2015) Performance-based probabilistic capacity models and fragility estimates for RC columns subject to vehicle collision. Comput Aided Civ Inf 30(7):555-569

50. Do TV, Pham TM, Hao H (2019) Impact force profile and failure classification of reinforced concrete bridge columns against vehicle impact. Eng Struct 183:443-458

51. Do TV, Pham TM, Hao H (2018) Numerical investigation of the behavior of precast concrete segmental columns subjected to vehicle collision. Eng Struct 156:375-393

52. Gholipour G, Zhang C, Mousavi AA (2018) Effects of axial load on nonlinear response of RC columns subjected to lateral impact load: ship-pier collision. Eng Fail Anal 91:397-418

53. Gholipour G, Zhang C, Li M (2018) Effects of soil-pile interaction on the response of bridge pier to barge collision using energy distribution method. Struct Infrastruct Eng 14(11):1520-1534

54. Gholipour G, Zhang C, Mousavi AA (2018) Analysis of girder bridge pier subjected to barge collision considering the superstructure interactions: the case study of a multiple-pier bridge system. Struct Infrastruct Eng 15(3):392-412

55. Gholipour G, Zhang C, Mousavi AA (2018) Reliability analysis of girder bridge piers subjected to barge collisions. Struct Infrastruct Eng 15(9):1200-1220
56. Fan W, Guo W, Sun Y, Chen B, Shao X (2018) Experimental and numerical investigations of a novel steel-UHPFRC composite fender for bridge protection in vessel collisions. Ocean Eng 165:1-21

57. Sha Y, Hao H (2013) Laboratory tests and numerical simulations of barge impact on circular reinforced concrete piers. Eng Struct 46:593-605

58. Song Y, Wang J (2019) Development of the impact force timehistory for determining the responses of bridges subjected to ship collisions. Ocean Eng 187:106182

59. Sha Y, Hao H (2012) Nonlinear finite element analysis of barge collision with a single bridge pier. Eng Struct 41:63-76

60. Wan Y, Zhu L, Fang H, Liu W, Mao Y (2019) Experimental testing and numerical simulations of ship impact on axially loaded reinforced concrete piers. Int J Impact Eng 125:246-262

61. Zhang J, Li X, Jing Y, Han W (2019) Bridge structure dynamic analysis under vessel impact loading considering soil-pile interaction and linear soil stiffness approximation. Adv Civ Eng 2019

62. Wang W, Morgenthal G (2017) Dynamic analyses of square RC pier column subjected to barge impact using efficient models. Eng Struct 151:20-32

63. Wang W, Morgenthal G (2018) Reliability analyses of RC bridge piers subjected to barge impact using efficient models. Eng Struct 166:485-495

64. Fan W, Yuan WC (2014) Numerical simulation and analytical modeling of pile-supported structures subjected to ship collisions including soil-structure interaction. Ocean Eng 91:11-27

65. Fan W, Yuan W, Yang Z, Fan Q (2010) Dynamic demand of bridge structure subjected to vessel impact using simplified interaction model. J Bridge Eng 16(1):117-126

66. Davidson MT, Consolazio GR, Getter DJ (2010) Dynamic amplification of pier column internal forces due to barge-bridge collision. Transp Res Rec 2172(1):11-22

67. Jiang H, Wang J, Chorzepa MG, Zhao J (2017) Numerical investigation of progressive collapse of a multispan continuous bridge subjected to vessel collision. J Bridge Eng 22(5):04017008

68. Madurapperuma MA, Wijeyewickrema AC (2013) Response of reinforced concrete columns impacted by tsunami dispersed 20 and 40 shipping containers. Eng Struct 56:1631-1644

69. He S, Yan S, Deng Y, Liu W (2019) Impact protection of bridge piers against rockfall. Bull Eng Geol Environ 78(4):2671-2680

70. Lu Y, Zhang L (2012) Analysis of failure of a bridge foundation under rock impact. Acta Geotech 7:57-68

71. Hartik IE, Shaaban AM, Gesund H, Valli GYS, Wang ST (1990) United States bridge failures, 1951-1988. J Perform Constr Fac 4(4):272-277

72. Wardhana K, Hadipriono FC (2003) Analysis of recent bridge failures in the United States. J Perform Constr Fac 17(3):144-150

73. Staples AM (2007) Pier protection. In: LRFD bridge design workshop, FL, USA

74. Al-Thairy H, Wang YC (2013) An assessment of the current Eurocode 1 design methods for building structure steel columns under vehicle impact. J Constr Steel Res 88:164-171

75. Milner R, Grzebieta R, Zou R (2001) Theoretical study of a motor vehicle-pole impact. In: Proceeding of road safety research, policing and education conference, Monash University, Melbourne, VIC, Australia

76. Vrouwenvelder T (2000) Stochastic modelling of extreme action events in structural engineering. Probab Eng Mech 15(1):109-117

77. ACI 318-14 (2014) Building code requirements for structural concrete and commentary. American Concrete Institute, Farmington Hills, MI, USA

78. Buth CE, Williams WF, Brackin MS, Lord D, Geedipally SR, Abu-Odeh AY (2010) Analysis of large truck collisions with 
bridge piers: phase 1. Report of guidelines for designing bridge piers and abutments for vehicle collisions. Texas Transportation Institution, College Station

79. Zhang X, Hao H, Li C (2016) Experimental investigation of the response of precast segmental columns subjected to impact loading. Int J Impact Eng 95:105-124

80. Do TV, Pham TM, Hao H (2019) Impact response and capacity of precast concrete segmental versus monolithic bridge columns. J Bridge Eng 24(6):04019050

81. Wikipedia (2001) Queen Isabella Causeway bridge disaster. https ://en.wikipedia.org/wiki/Queen_Isabella_Causeway

82. Wikipedia (2002) I-40 bridge disaster. http://en.wikipedia.org/ wiki/I-40_bridge_disaster

83. Stpetecatalyst (2019) https://stpetecatalyst.com/rememberin g-the-skyway-bridge-disaster-39-years-later/

84. Consolazio GR, Cowan DR, Biggs A, Cook RA, Ansley M, Bollmann HT (2005) Full-scale experimental measurement of barge impact loads on bridge piers. Transp Res Rec 1936(1):80-93

85. Consolazio GR, Cook RA, Lehr GB (2002) Barge impact testing of the St. George Island causeway bridge. Phase I: feasibility study. Research report no. BC-354 RPWO-23, Engineering and Industrial Experiment Station, University of Florida, Gainesville, FL, USA:

86. Consolazio GR, Cook RA, Biggs AE, Cowan DR (2003) Barge impact testing of the St. George Island causeway bridge. Phase II: design of instrumentation systems. Research report no. BC-354 RPWO-56, Engineering and Industrial Experiment Station, University of Florida, Gainesville, FL, USA

87. Consolazio GR, Cook RA, McVay MC, Cowan D, Biggs A, Bui L (2006) Barge impact testing of the St. George Island Causeway Bridge, Phase III: physical testing and data interpretation. Research report no. BC-354 RPWO-76, Engineering and Industrial Experiment Station, University of Florida, Gainesville, FL, USA

88. McVay MC, Wasman SJ, Bullock PJ (2005) Barge impact testing of St. George Island Causeway Bridge geotechnical investigation. Research report no. BD-545 RPWO-05, Engineerin and Industrial Experiment Station, University of Florida Gainesville, FL, USA

89. Consolazio GR, McVay MC, Cowan DR, Davidson MT, Getter DJ (2008) Development of improved bridge design provisions for barge impact loading. Research report no. BD-545 RPWO-29, University of Florida. Department of Civil and Coastal Engineering, FL, USA

90. Consolazio GR, Getter DJ, Davidson MT (2009) A static analysis method for barge-impact design of bridges with consideration of dynamic amplification. Research report no. BD-545 RPWO-85, University of Florida. Department of Civil and Coastal Engineering, FL, USA

91. Consolazio GR, Davidson MT, Getter DJ (2010) Vessel crushing and structural collapse relationships for bridge design. Research report no. 2010/72908/74039, University of Florida, Department of Civil and Coastal Engineering, FL, USA

92. Consolazio GR, Getter DJ, Kantrales GC (2014) Validation and implementation of bridge design specifications for barge impact loading. Research report no. BDK75-977-31, University of Florida. Department of Civil and Coastal Engineering, FL, USA

93. Hendrix JL (2003) Dynamic analysis techniques for quantifying bridge pier response to barge impact loads. Master of Engineering Thesis, University of Florida, FL, USA

94. Consolazio GR, Cowan DR (2005) Numerically efficient dynamic analysis of barge collisions with bridge piers. J Struct Eng 131(8):1256-1266
95. Consolazio GR, Davidson MT, Cowan DR (2009) Barge bow force-deformation relationships for barge-bridge collision analysis. Transp Res Rec 2131:3-14

96. Consolazio GR, Davidson MT (2008) Simplified dynamic analysis of barge collision for bridge design. Transp Res Rec 2050(1):13-25

97. Fan W, Yuan WC, Zhou M (2011) A nonlinear dynamic macroelement for demand assessment of bridge substructures subjected to ship collision. J Zhejiang Univ Sci A 12(11):826-836

98. Consolazio GR, Cowan DR (2003) Nonlinear analysis of barge crush behavior and its relationship to impact resistant bridge design. Comput Struct 81:547-557

99. Yuan P, Harik IE (2010) Equivalent barge and flotilla impact forces on bridge piers. J Bridge Eng 15(5):523-532

100. Getter D, Consolazio G (2011) Relationships of barge bow forcedeformation for bridge design: probabilistic consideration of oblique impact scenarios. Transp Res Rec 2251(1):3-15

101. Fan W, Yuan W (2014) Ship bow force-deformation curves for ship-impact demand of bridges considering effect of pile-cap depth. Shock Vib 2014

102. Kantrales GC, Consolazio GR, Wagner D, Fallaha S (2016) Experimental and analytical study of high-level barge deformation for barge-bridge collision design. J Bridge Eng 21(2):04015039

103. Luperi FJ, Pinto F (2016) Structural behavior of barges in high energy collisions against bridge piers. J Bridge Eng 21(2):04015049

104. Sha Y, Hao H (2014) A simplified approach for predicting bridge pier responses subjected to barge impact loading. Adv Struct Eng 17(1):11-23

105. Yuan P, Harik IE, Davidson MT (2008) Multi-barge flotilla impact forces on bridges. Report no. KTC-08-13/SPR261-03-2F. Lexington, Kentucky: Kentucky Transportation Center College of Engineering, University of Kentucky, USA

106. Consolazio GR, Hendrix JL, McVay MC, Williams ME (1868) Bollmann HT (2004) Prediction of pier response to barge impacts with design-oriented dynamic finite element analysis. Transp Res Rec 1:177-189

107. Fan W, Liu Y, Liu B, Guo W (2015) Dynamic ship-impact load on bridge structures emphasizing shock spectrum approximation. J Bridge Eng 21(10):04016057

108. Fan W, Zhang Y, Liu B (2016) Modal combination rule for shock spectrum analysis of bridge structures subjected to barge collisions. J Eng Mech 142(2):04015083

109. Fan W, Yuan WC (2012) Shock spectrum analysis method for dynamic demand of bridge structures subjected to barge collisions. Comput Struct 90:1-12

110. Davidson MT, Consolazio GR, Getter DJ, Shah FD (2013) Probability of collapse expression for bridges subject to barge collision. J Bridge Eng 18(4):287-296

111. Cheng J (2014) Reliability analysis of the Sutong Bridge Tower under ship impact loading. Struct Infrastruct E 10(10):1320-1329

112. Shao JH, Zhao RD, Geng B (2015) Probabilistic analysis of bridge collapse during ship collisions based on reliability theory. J Highw Transp Res Dev 9(1):55-62

113. Koh HM, Lim JH, Kim H, Yi J, Park W, Song J (2017) Reliability-based structural design framework against accidental loadsship collision. Struct Infrastruct Eng 13(1):171-180

114. Kameshwar S, Padgett JE (2018) Response and fragility assessment of bridge columns subjected to barge-bridge collision and scour. Eng Struct 168:308-319

115. Getter DJ, Consolazio GR, Davidson MT (2011) Equivalent static analysis method for barge impact-resistant bridge design. J Bridge Eng 16(6):718-727 
116. Bui LH (2005) Static versus dynamic structural response of bridge piers to barge collision loads. Ph.D. thesis, University of Florida, FL, USA.

117. McVay MC, Wasman SJ, Consolazio GR, Bullock PJ, Cowan DG, Bollmann HT (2009) Dynamic soil-structure interaction of bridge substructure subject to vessel impact. J Bridge Eng 14(1):7-16

118. Aziz HY, Yong HY, Mauls BH (2017) Dynamic Response of bridge-ship collision considering pile-soil interaction. Civ Eng J 3(10):965-971

119. Wang W, Morgenthal G (2019) Parametric studies of pile-supported protective structures subjected to barge impact using simplified models. Mar Struct 63:138-152

120. Gholipour G, Zhang C, Mousavi AA (2020) Nonlinear numerical analysis and progressive damage assessment of a cable-stayed bridge pier subjected to ship collision. Mar Struct 69:102662

121. Tian L, Huang F (2014) Numerical simulation for progressive collapse of continuous girder bridge subjected to ship impact. Trans Tianjin Univ 20(4):250-256

122. Tian L, Huang F (2013) Numerical simulation for progressive collapse of continuous girder bridge subjected to ship collision based on three-stage simulation method. Adv Mater Res 790:362-366

123. Liu B, Fan W, Guo W, Chen B, Liu R (2017) Experimental investigation and improved FE modeling of axially-loaded circular RC columns under lateral impact loading. Eng Struct 152:619-642

124. Remennikov A, Kaewunruen S (2006) Impact resistance of reinforced concrete columns: experimental studies and design considerations. Faculty of Engineering, University of Wollongong, Wollongong

125. Yilmaz T, Kiraç N, Anil Ö (2019) Experimental investigation of axial loaded reinforced concrete square column subjected to lateral low-velocity impact loading. Struct Concr 1-21

126. Parvin A, Brighton D (2014) FRP composites strengthening of concrete columns under various loading conditions. Polymers 6(4):1040-1056

127. Harris B, Beaumont PWR (1971) Moncunill de Ferran E. Strength and fracture toughness of carbon fibre polyester composites. J Mater Sci 6(3):238-251

128. Hayes SV, Adams DF (1982) Rate sensitive tensile impact properties of fully and partially loaded unidirectional composites. J Test Eval 10(2):61-68

129. Hancox NL (1971) Izod impact testing of carbon-fibre-reinforced plastics. Composites 2(1):41-45

130. Kimura H, Itabashi M, Kawata K (2001) Mechanical characterization of unidirectional CFRP thin strip and CFRP cables under quasi-static and dynamic tension. Adv Compos Mater 10(2/3):177-187

131. Cantwell WJ, Smith K (1999) The static and dynamic response of CFRP-strengthened concrete structures. J Mater Sci Lett 18(4):309-310

132. Yan X, Yali S (2012) Impact behaviors of CFT and CFRP confined CFT stub columns. J Compos Constr 16(6):662-670

133. Alam MI, Fawzia S, Zhao XL, Remennikov AM (2017) Experimental study on FRP-strengthened steel tubular members under lateral impact. J Compos Constr 21(5):04017022

134. Yoo DY, Banthia N (2017) Mechanical and structural behaviors of ultra-high-performance fiber-reinforced concrete subjected to impact and blast. Constr Build Mater 149:416-431

135. Fan W, Shen D, Yang T, Shao X (2019) Experimental and numerical study on low-velocity lateral impact behaviors of RC, UHPFRC and UHPFRC-strengthened columns. Eng Struct 191:509-525
136. Wang R, Han LH, Hou CC (2013) Behavior of concrete filled steel tubular (CFST) members under lateral impact: experiment and FEA model. J Constr Steel Res 80:188-201

137. Huo JS, Zheng Q, Chen BS, Xiao Y (2009) Tests on impact behaviour of micro-concrete-filled steel tubes at elevated temperatures up to $400{ }^{\circ} \mathrm{C}$. Mater Struct 42(10):1325-1334

138. Han LH, Hou CC, Zhao XL, Rasmussen KJ (2014) Behaviour of high-strength concrete filled steel tubes under transverse impact loading. J Constr Steel Res 92:25-39

139. Bambach MR (2011) Design of hollow and concrete filled steel and stainless steel tubular columns for transverse impact loads. Thin Wall Struct 49(10):1251-1260

140. Alam MI, Fawzia S, Zhao XL (2016) Numerical investigation of CFRP strengthened full scale CFST columns subjected to vehicular impact. Eng Struct 126:292-310

141. Zhang X, Chen Y, Wan J, Wang K, He K, Chen X, Wei J, Jiang $\mathrm{G}$ (2018) Tests on residual ultimate bearing capacity of square CFST columns after impact. J Constr Steel Res 147:27-42

142. Zhu AZ, Xu W, Gao K, Ge HB, Zhu JH (2018) Lateral impact response of rectangular hollow and partially concrete-filled steel tubular columns. Thin Wall Struct 130:114-131

143. Aghdamy S, Thambiratnam DP, Dhanasekar M, Saiedi S (2015) Computer analysis of impact behavior of concrete filled steel tube columns. Adv Eng Softw 89:52-63

144. Bambach MR, Jama H, Zhao XL, Grzebieta RH (2008) Hollow and concrete filled steel hollow sections under transverse impact loads. Eng Struct 30(10):2859-2870

145. Qu H, Li G, Chen S, Sun J, Sozen MA (2011) Analysis of circular concrete-filled steel tube specimen under lateral impact. Adv Struct Eng 14(5):941-951

146. Shan JH, Chen R, Zhang WX, Xiao Y, Yi WJ, Lu FY (2007) Behavior of concrete filled tubes and confined concrete filled tubes under high speed impact. Adv Struct Eng 10(2):209-218

147. Wang R, Han LH, Zhao XL, Rasmussen KJ (2015) Experimental behavior of concrete filled double steel tubular (CFDST) members under low velocity drop weight impact. Thin Wall Struct 97:279-295

148. Wang R, Han LH, Zhao XL, Rasmussen KJ (2016) Analytical behavior of concrete filled double steel tubular (CFDST) members under lateral impact. Thin Wall Struct 101:129-140

149. Aghdamy S, Thambiratnam DP, Dhanasekar M, Saiedi S (2017) Effects of load-related parameters on the response of concretefilled double-skin steel tube columns subjected to lateral impact. J Constr Steel Res 138:642-662

150. Aghdamy S, Thambiratnam DP, Dhanasekar M, Saiedi S (2016) Effects of structure-related parameters on the response of concrete-filled double-skin steel tube columns to lateral impact. Thin Wall Struct 108:351-368

151. Du G, Andjelic A, Li Z, Lei Z, Bie X (2018) Residual axial bearing capacity of concrete-filled circular steel tubular columns (CFCSTCs) after transverse impact. Appl Sci 8(5):793

152. Yousuf M, Uy B, Tao Z, Remennikov A, Liew JR (2013) Transverse impact resistance of hollow and concrete filled stainless steel columns. J Constr Steel Res 82:177-189

153. Yousuf M, Uy B, Tao Z, Remennikov A, Liew JR (2014) Impact behaviour of pre-compressed hollow and concrete filled mild and stainless steel columns. J Constr Steel Res 96:54-68

154. Yang YF, Zhang ZC, Fu F (2015) Experimental and numerical study on square RACFST members under lateral impact loading. J Constr Steel Res 111:43-56

155. Shakir AS, Guan ZW, Jones SW (2016) Lateral impact response of the concrete filled steel tube columns with and without CFRP strengthening. Eng Struct 116:148-162

156. Alam MI, Fawzia S, Liu X (2015) Effect of bond length on the behaviour of CFRP strengthened concrete-filled steel tubes under transverse impact. Compos Struct 132:898-914 
157. Chen C, Zhao Y, Li J (2014) Experimental investigation on the impact performance of concrete-filled FRP steel tubes. J Eng Mech 141(2):04014112

158. Wang R, Han LH, Tao Z (2015) Behavior of FRP-concrete-steel double skin tubular members under lateral impact: experimental study. Thin Wall Struct 95:363-373

159. Soleimani SM, Sayyar Roudsari S (2019) Analytical study of reinforced concrete beams tested under quasi-static and impact loadings. Appl Sci 9(14):2838

160. Fujikake K, Senga T, Ueda N, Ohno T, Katagiri M (2006) Study on impact response of reactive powder concrete beam and its analytical model. J Adv Concr Technol 4(1):99-108

161. Pham TM, Hao H (2016) Prediction of the impact force on reinforced concrete beams from a drop weight. Adv Struct Eng 19(11):1710-1722

162. Bischoff PH, Perry SH, Eibl J (1990) Contact force calculations with a simple spring-mass model for hard impact: a case study using polystyrene aggregate concrete. Int J Impact Eng 9(3):317-325

163. Zhao W, Qian J, Jia P (2019) Peak Response prediction for RC beams under impact loading. Shock Vib 2019.

164. Kishi N, Mikami H (2012) Empirical formulas for designing reinforced concrete beams under impact loading. ACI Struct J 109(4):509-519

165. Bhatti AQ, Kishi $N$ (2010) Impact response of RC rock-shed girder with sand cushion under falling load. Nucl Eng Des 240(10):2626-2632

166. Tachibana S, Masuya H, Nakamura S (2010) Performance based design of reinforced concrete beams under impact. Nat Hazard Earth Syst 10(6):1069-1078

167. Zhang C, Gholipour G, Mousavi AA (2019) Nonlinear dynamic behavior of simply-supported RC beams subjected to combined impact-blast loading. Eng Struct 181:124-142

168. Gholipour G, Zhang C, Mousavi AA (2019) Loading rate effects on the responses of simply supported RC beams subjected to the combination of impact and blast loads. Eng Struct 201:109837

169. Jin L, Xu J, Zhang R, Du X (2017) Numerical study on the impact performances of reinforced concrete beams: a mesoscopic simulation method. Eng Fail Anal 80:141-163

170. Guo J, Cai J, Chen W (2017) Inertial effect on RC beam subjected to impact loads. Int J Struct Stab Dyn 17(04):1750053

171. Tantrapongsaton $\mathrm{W}$, Hansapinyo $\mathrm{C}$, Wongmatar $\mathrm{P}$, Chaisomphob $\mathrm{T}$ (2018) Flexural reinforced concrete members with minimum reinforcement under low-velocity impact load. Int J Geomate 14(46):129-136

172. Li H, Chen W, Hao H (2019) Dynamic response of precast concrete beam with wet connection subjected to impact loads. Eng Struct 191:247-263

173. Kong X, Fang Q, Chen L, Wu H (2018) Nonlocal formulation of the modified $\mathrm{K} \& \mathrm{C}$ model to resolve mesh-size dependency of concrete structures subjected to intense dynamic loadings. Int $\mathbf{J}$ Impact Eng 122:318-332

174. Li H, Chen W, Hao H (2019) Influence of drop weight geometry and interlayer on impact behavior of RC beams. Int J Impact Eng 131:222-237

175. Pham TM, Hao H (2017) Effect of the plastic hinge and boundary conditions on the impact behavior of reinforced concrete beams. Int J Impact Eng 102:74-85

176. Pham TM, Hao H (2017) Plastic hinges and inertia forces in RC beams under impact loads. Int J Impact Eng 103:1-11

177. Kishi N, Nakano O, Matsuoka KG, Anto T (2001) Experimental study on ultimate strength of flexural-failure-type RC beams under impact loading. In: Transactions of 16th international conference on structural mechanics in reactor technology, International Association for Structural Mechanics in Reactor Technology, Raleigh, NC, USA
178. Li Y, Wang X, Guo X (2006) Experimental study on anti-impact properties of a partially prestressed concrete beam. Explos Shock Waves 26:256

179. Ishikawa N, Enrin H, Katsuki S, Ohta T (1998) Dynamic behavior of prestressed concrete beams under rapid speed loading. Struct Under Shock Impact 5:717-726

180. Ishikawa N, Katsuki S, Takemoto K (2002) Incremental impact test and simulation of prestressed concrete beam. Struct Mater $11: 489-498$

181. Isaac P, Darby A, Ibell T, Evernden M (2017) Experimental investigation into the force propagation velocity due to hard impacts on reinforced concrete members. Intl J Impact Eng 100:131-138

182. Liao W, Li M, Zhang W, Tian Z (2017) Experimental studies and numerical simulation of behavior of RC beams retrofitted with HSSWM-HPM under impact loading. Eng Struct 149:131-146

183. Yan Q, Sun B, Liu X, Wu J (2018) The effect of assembling location on the performance of precast concrete beam under impact load. Adv Struct Eng 21(8):1211-1222

184. Guo J, Cai J, Chen Q, Liu X, Wang Y, Zuo Z (2019) Dynamic behaviour and energy dissipation of reinforced recycled aggregate concrete beams under impact. Constr Build Mater 214:143-157

185. Adhikary SD, Li B, Fujikake K (2015) Low velocity impact response of reinforced concrete beams: experimental and numerical investigation. Int J Protect Struct 6(1):81-111

186. Zhao DB, Yi WJ, Kunnath SK (2017) Shear mechanisms in reinforced concrete beams under impact loading. J Struct Eng 143(9):04017089

187. Guo W, Fan W, Shao X, Shen D, Chen B (2018) Constitutive model of ultra-high-performance fiber-reinforced concrete for low-velocity impact simulations. Compos Struct 185:307-326

188. Cotsovos DM, Stathopoulos ND, Zeris CA (2008) Behavior of RC beams subjected to high rates of concentrated loading. J Struct Eng 134(12):1839-1851

189. Cotsovos DM (2010) A simplified approach for assessing the load-carrying capacity of reinforced concrete beams under concentrated load applied at high rates. Int J Impact Eng 37(8):907-917

190. Cotsovos DM, Pavlović MN (2008) Numerical investigation of concrete subjected to compressive impact loading, Part 1: A fundamental explanation for the apparent strength gain at high loading rates. Comput Struct 86(1-2):145-163

191. Zhan T, Wang Z, Ning J (2015) Failure behaviors of reinforced concrete beams subjected to high impact loading. Eng Fail Anal $56: 233-243$

192. Ožbolt J, Sharma A (2011) Numerical simulation of reinforced concrete beams with different shear reinforcements under dynamic impact loads. Int J Impact Eng 38(12):940-950

193. Pham TM, Hao Y, Hao H (2018) Sensitivity of impact behaviour of RC beams to contact stiffness. Int J Impact Eng 112:155-164

194. Zhao DB, Yi WJ, Kunnath SK (2018) Numerical simulation and shear resistance of reinforced concrete beams under impact. Eng Struct 166:387-401

195. Yi WJ, Zhao DB, Kunnath SK (2016) Simplified approach for assessing shear resistance of reinforced concrete beams under impact loads. ACI Struct J 113(4):747-756

196. Fan W, Liu B, Huang X, Sun Y (2019) Efficient modeling of flexural and shear behaviors in reinforced concrete beams and columns subjected to low-velocity impact loading. Eng Struct 195:22-50

197. Pham TM, Hao H (2017) Behavior of fiber-reinforced polymerstrengthened reinforced concrete beams under static and impact loads. Int J Protect Struct 8(1):3-24

198. Pham TM, Hao H (2016) Impact behavior of FRP-strengthened RC beams without stirrups. J Compos Constr 20(4):04016011 
199. Hao Y, Hao H, Chen G (2016) Experimental investigation of the behaviour of spiral steel fibre reinforced concrete beams subjected to drop-weight impact loads. Mater Struct 49(1-2):353-370

200. Jerome DM (1996) Dynamic response of concrete beams externally reinforced with carbon fiber reinforced plastic. University of Florida, Gainesville

201. Wang WW, Dai JG, Harries KA (2011) Performance evaluation of RC beams strengthened with an externally bonded FRP system under simulated vehicle loads. J Bridge Eng 18(1):76-82

202. Erki MA, Meier U (1999) Impact loading of concrete beams externally strengthened with CFRP laminates. J Compos Constr 3(3):117-124

203. Goldston MW, Remennikov A, Saleh Z, Sheikh MN (2019) Experimental investigations on the behavior of GFRP bar reinforced HSC and UHSC beams under static and impact loading. Structures 22:109-123

204. Anil Ö, Durucan C, Erdem RT, Yorgancilar MA (2016) Experimental and numerical investigation of reinforced concrete beams with variable material properties under impact loading. Constr Build Mater 125:94-104

205. Wang W, Chouw N (2017) Behaviour of CFRC beams strengthened by FFRP laminates under static and impact loadings. Constr Build Mater 155:956-964

206. Hrynyk TD, Vecchio FJ (2014) Behavior of steel fiber-reinforced concrete slabs under impact load. ACI Struct J 111(5):1213

207. Verma M, Prem PR, Rajasankar J, Bharatkumar BH (2016) On low-energy impact response of ultra-high performance concrete (UHPC) panels. Mater Des 92:853-865

208. Anil Ö, Kantar E, Yilmaz MC (2015) Low velocity impact behavior of RC slabs with different support types. Constr Build Mater 93:1078-1088

209. Goswami A, Adhikary SD, Li B (2019) Predicting the punching shear failure of concrete slabs under low velocity impact loading. Eng Struct 184:37-51

210. Yılmaz T, Kıraç N, Anil Ö, Erdem RT, Sezer C (2018) Lowvelocity impact behaviour of two way RC slab strengthening with CFRP strips. Constr Build Mater 186:1046-1063

211. Othman H, Marzouk H (2020) An experimental investigation on the effect of steel reinforcement on impact response of reinforced concrete plates. Int J Impact Eng 88:12-21

212. Wang W, Chouw N (2016) Experimental and theoretical studies of flax FRP strengthened coconut fibre reinforced concrete slabs under impact loadings. Constr Build Mater 171:546-557

213. Thai DK, Kim SE (2017) Numerical simulation of pre-stressed concrete slab subjected to moderate velocity impact loading. Eng Fail Anal 79:820-835

214. Thai DK, Kim SE, Bui TQ (2018) Modified empirical formulas for predicting the thickness of RC panels under impact loading. Constr Build Mater 169:261-275

215. Micallef K, Sagaseta J, Ruiz MF, Muttoni A (2014) Assessing punching shear failure in reinforced concrete flat slabs subjected to localised impact loading. Int J Impact Eng 71:17-33

216. Guo Q, Zhao W (2019) Displacement response analysis of steelconcrete composite panels subjected to impact loadings. Int J Impact Eng 131:272-281

217. Ožbolt J, Ruta D, İrhan B (2019) Impact analysis of thermally pre-damaged reinforced concrete slabs: verification of the 3D FE model. Int J Impact Eng 133:103343

218. Iqbal MA, Kumar V, Mittal AK (2019) Experimental and numerical studies on the drop impact resistance of prestressed concrete plates. Int J Impact Eng 123:98-117
219. Kumar V, Iqbal MA, Mittal AK (2018) Study of induced prestress on deformation and energy absorption characteristics of concrete slabs under drop impact loading. Constr Build Mater 188:656-675

220. Tahmasebinia F, Remennikov A (2008) Simulation of the reinforced concrete slabs under impact loading. In: Australian structural engineering conference, Melbourne, Australia

221. Rao HS, Ghorpade VG, Ramana NV, Gnaneswar K (2010) Response of SIFCON two-way slabs under impact loading. Int J Impact Eng 37(4):452-458

222. Kong X, Fang Q, Li QM, Wu H, Crawford JE (2017) Modified $\mathrm{K} \& \mathrm{C}$ model for cratering and scabbing of concrete slabs under projectile impact. Int J Impact Eng 108:217-228

223. Rajput A, Iqbal MA (2017) Ballistic performance of plain, reinforced and pre-stressed concrete slabs under normal impact by an ogival-nosed projectile. Int J Impact Eng 110:57-71

224. Iqbal MA, Rajput A, Gupta NK (2017) Performance of prestressed concrete targets against projectile impact. Int J Impact Eng 110:15-25

225. Almusallam TH, Siddiqui NA, Iqbal RA, Abbas H (2013) Response of hybrid-fiber reinforced concrete slabs to hard projectile impact. Int J Impact Eng 58:17-30

226. Pavlovic A, Fragassa C, Disic A (2017) Comparative numerical and experimental study of projectile impact on reinforced concrete. Compos B Eng 108:122-130

227. Xu X, Ma T, Ning J (2019) Failure analytical model of reinforced concrete slab under impact loading. Constr Build Mater 223:679-691

228. Almusallam TH, Abadel AA, Al-Salloum YA, Siddiqui NA, Abbas H (2015) Effectiveness of hybrid-fibers in improving the impact resistance of RC slabs. Int J Impact Eng 81:61-73

229. Vossoughi F, Ostertag CP, Monteiro PJ, Johnson GC (2007) Resistance of concrete protected by fabric to projectile impact. Cem Concr Res 37(1):96-106

230. Mousa MA, Uddin N (2014) Response of CFRP/AAC sandwich structures under low velocity impact. ACI Mater J 111(1):99-109

231. Wang XD, Zhang C, Huang Z, Chen GW (2013) Impact experimental research on hybrid bamboo fiber and steel fiber reinforced concrete. Appl Mech Mater 357:1049-1052

232. Wang W, Chouw N (2017) The behaviour of coconut fibre reinforced concrete (CFRC) under impact loading. Constr Build Mater 134:452-461

233. Sadraie H, Khaloo A, Soltani H (2019) Dynamic performance of concrete slabs reinforced with steel and GFRP bars under impact loading. Eng Struct 191:62-81

234. Gholipour G, Zhang C, Mousavi AA (2020) Numerical analysis of axially loaded RC columns subjected to the combination of impact and blast loads. Eng Struct 219:110924

235. Zhang C, Gholipour G, Mousavi AA (2020) Blast loads induced responses of RC structural members: State-of-the-art review. Compos Part B: Eng 195:108066

Publisher's Note Springer Nature remains neutral with regard to jurisdictional claims in published maps and institutional affiliations. 